\title{
Spatiotemporal variation of nitrogen and phosphorus and its main influencing factors in Huangshui River basin
}

\author{
Biqiong Dong • Tianling Qin • Yu Wang • \\ Yan Zhao $\cdot$ Shanshan Liu $\cdot$ Jianming Feng $\cdot$ \\ Chenhao Li $\cdot$ Xin Zhang
}

Received: 10 November 2020 / Accepted: 11 April 2021 / Published online: 23 April 2021

(C) The Author(s) 2021

\begin{abstract}
The foundation of managing excess nutrients in river is the identification of key physical processes and the control of decisive influencing factors. The existing studies seldom consider the influence of rainfall-runoff relationship and only focus on a few anthropogenic activities and natural attributes factors. To address this issue, a comprehensive set of influencing factors including rainfall-runoff relationship (represented by runoff coefficient), basic physical and chemical parameters of water quality, land use types, landscape patterns, topography, and socioeconomic development was constructed in this study. $\mathrm{M}-\mathrm{K}$ test and cluster analysis were conducted to identify the
\end{abstract}

Supplementary information The online version contains supplementary material available at https://doi. org/10.1007/s10661-021-09067-1.

B. Dong $\cdot$ T. Qin $(\bowtie) \cdot S$. Liu $\cdot$ X. Zhang

State Key Laboratory of Simulation and Regulation of Water Cycle in River Basin, China Institute of Water Resources and Hydropower Research, Beijing, China e-mail: qintl@iwhr.com

B. Dong

e-mail: bqdong92@126.com

S. Liu

e-mail: liushanshan198705@163.com

X. Zhang

e-mail: 838320922@qq.com

Y. Wang $\cdot$ Y. Zhao

Yellow River Institute of Hydraulic Research, Yellow temporal mutation and spatial clustering characteristics of $\mathrm{NH}_{3}-\mathrm{N}$ and TP in Huangshui River basin, respectively. Partial least squares regression was used to elucidate the linkages between water contaminants and the factors. As shown in the results, the temporal mutations of $\mathrm{NH}_{3}-\mathrm{N}$ and TP were obvious in the middle reaches, with 4 out of 7 catchments in the middle reaches have a larger number of mutations of $\mathrm{NH}_{3}-\mathrm{N}$ than other catchments. The cluster analysis results of $\mathrm{NH}_{3}-\mathrm{N}$ and TP among catchments were similar. This study also indicated that although the Huangshui River basin was located in the upper reaches of the Yellow River, the influences of rainfall-runoff relationship on spatiotemporal changes of $\mathrm{NH}_{3}-\mathrm{N}$ and TP in its sub-basins were limited. Only the temporal change of $\mathrm{NH}_{3}-\mathrm{N}$ in Jintan catchment in the upstream

River Engineering Consulting Co., Ltd., Zhengzhou, China e-mail: yuwang@163.com

Y. Zhao

e-mail: wssf9303@163.com

J. Feng $\cdot$ C. Li

College of Resource Environment and Tourism, Capital

Normal University, Beijing, China

e-mail: 13607975061@163.com

C. $\mathrm{Li}$

e-mail: lchbjji@hotmail.com 
area was significantly affected by runoff coefficient. The indexes of proportion of water area (PWA), proportion of impervious area (PIA), and proportion of primary industry (PPI) were the top three influencing factors of temporal variation of $\mathrm{NH}_{3}-\mathrm{N}$ and TP for most catchments in the middle reaches. The temporal change of $\mathrm{NH}_{3}-\mathrm{N}$ in Jintan catchment in the upstream area was obviously affected by runoff coefficient. The spatial variation of $\mathrm{NH}_{3}-\mathrm{N}$ and TP were all affected by PWA and proportion of secondary industry significantly. The results of this study can provide theoretical basis and technical support for the control and management of nitrogen and phosphorus pollution in upper reaches of rivers.

Keywords Ammonia nitrogen - Total phosphorus · Spatiotemporal variation - Influencing factor set . Partial least squares regression · Huangshui River basin

\section{Introduction}

Prevention and control of river nitrogen and phosphorus pollution is one of the key issues to achieve sustainable river basin planning and management (Reichwaldt \& Ghadouani, 2016; Srinivas et al., 2020). While the effectiveness of the prevention and control depends on the accurate identification of main influencing factors of pollution. Previous studies shows that the concentration of nitrogen and phosphorus in streams are regulated by a complex suite of anthropogenic activities and natural attributes (Dupas et al., 2018; Hobbie et al., 2017; Liu et al., 2018; Outram et al., 2016; Pathak et al., 2018; Pennino et al., 2016; Xia et al., 2018). However, the relative importance of different influencing factors varies in different studies especially for the upper reaches of rivers. To identify the main influencing factors which affect the spatiotemporal variation of nitrogen and phosphorus in the upper reaches of rivers, it is essential to analyze based on key physical processes. In general, the spatiotemporal variation of nitrogen and phosphorus in riverine water is driven by three key processes (Guo et al., 2019) (Fig. 1): (1) Source: the amount of the constituent within the catchment. Different land use types and socioeconomic development factors (such as the distribution of population, livestock and gross regional domestic product) are related to source and load of nitrogen and phosphorous
(Li et al., 2020). (2) Mobilization: the detachment of these constituents from the source, due to weathering, erosion or biogeochemical process. The precipitation or streamflow influences the mobilization of constituents in the catchment (Mellander et al., 2015). Different land use types may cause different biogeochemical processes of nitrogen and phosphorous (Pellerin et al., 2004; Zhou et al., 2012). The basic physical and chemical parameters of water quality such as $\mathrm{pH}, \mathrm{DO}$, and $\mathrm{COD}_{\mathrm{Mn}}$ influence the transformation and mobilization of nitrogen and phosphorus in rivers (Shi et al., 2016; Zhang et al., 2011). (3) Delivery: the transport of mobilized constituents from the catchment to receiving waters. The precipitation or streamflow affects the temporal variability in the delivery of the constituent to receiving waters (Guo et al., 2019). Land use types conversion significantly impacts hydrological variables, and landscape patterns affect the transport rates of allochthonous material, which both influence the transportation of nitrogen and phosphorous (Nielsen et al., 2012; Xu et al., 2019a, b). Topographic characteristics, such as elevation and slope, partly determine the transport path of pollutants from diffuse sources to rivers, especially on slope (Shi et al., 2016).

Some scholars have carried out investigations based on the identification of the abovementioned key physical processes. The impacts of basic physical and chemical parameters of water quality (Shi et al., 2016; Zhang et al., 2011), precipitation or runoff (Guo et al., 2019; Nobre et al., 2020; Shi et al., 2016), land use (Ai et al., 2015; Alvarez-Cobelas et al., 2008; Jabbar \& Grote, 2019; Nobre et al., 2020; Rodrigues et al., 2018; Shi et al., 2016; Xu et al., 2019b), landscape patterns (Ai et al., 2015; Li et al., 2020; Nobre et al., 2020; Xiao et al., 2016; Xu et al., 2019a), topography (Jabbar \& Grote, 2019; Shi et al., 2016), and socioeconomic development (Alvarez-Cobelas et al., 2008; Rattan et al., 2017; Wang et al., 2019) factors on the spatiotemporal variation of nitrogen or phosphorous were analyzed. However, the existing studies seldom consider the influence of rainfall-runoff relationship in the upper reaches of rivers and focus on a few aforementioned factors. There is a lack of a more comprehensive set of influencing factors which includes rainfall-runoff relationship to explore its impact on the spatiotemporal variation of nitrogen and phosphorus and to identify the key factors. Regarding the identification method of key factors, gray relational analysis (Zhang et al., 2011), redundancy analysis (Xu et al., 


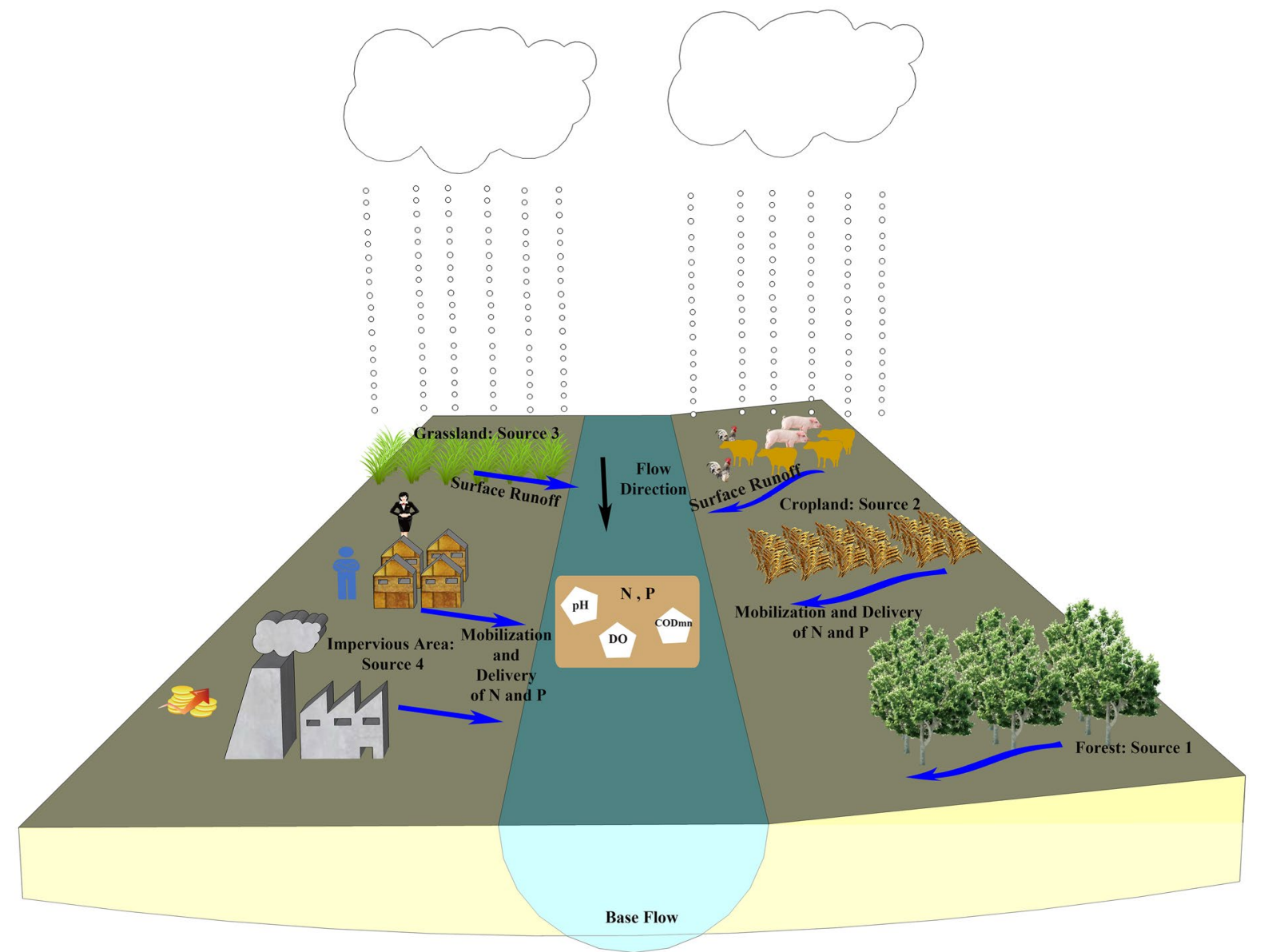

Fig. 1 Schematic diagram of the key processes which drive the spatiotemporal variation of nitrogen and phosphorus in river

2019a), factor analysis (Luo et al., 2017), correlation analysis (Cui et al., 2020; Xiao et al., 2016), Bayesian networks (BNs) (Xu et al., 2019b), Bayesian hierarchical model methods (Guo et al., 2019), multiple linear regression analysis (Mayora et al., 2018; Shi et al., 2016), principal component analysis (Han et al., 2020), and partial least squares regression (AlvarezCobelas et al., 2008; Rattan et al., 2017) were used in various studies. The gray relational analysis method is deficient in non-standardization and non-isotonicity in the calculation of the correlation degree (Zhou, 2007). The redundancy analysis model searches for the linear combination of the independent set that maximizes the redundancy index (Oliveira et al., 2004). Factor analysis is a statistical method to extract common factors from variable groups, and correlation analysis focuses on discovering the correlation characteristics between random variables. Bayesian networks and Bayesian hierarchical model methods are suitable for large-scale data sets with vast parameters (Guo et al., 2019; Xu et al., 2019b) Although both belong to multiple linear regression analysis, partial least squares regression performs better in solving the multicollinearity problem of independent variables than Principal component analysis (Carrascal et al., 2009).

In this study, a comprehensive set of influencing factors which consisted of six types of factors including rainfall-runoff relationship (represented by runoff coefficient), basic physical and chemical parameters of water quality, land use types, landscape patterns, topography, and socioeconomic development were constructed. To test whether it is applicable to the upper reaches of rivers, we selected Huangshui River basin in the upper reaches 
of the Yellow River as an example. According to China Ecological and Environmental Status Bulletin from 2015 to 2018 (Ministry of Ecology and Environment of the People's Republic of China, 2018), the main water quality pollution indexes in the Yellow River basin, $\mathrm{NH}_{3}-\mathrm{N}$, and $\mathrm{TP}$, were selected as the indicators of nitrogen and phosphorus pollution in this study. Based on Matlab platform, the temporal mutation characteristics and the spatial clustering characteristics of $\mathrm{NH}_{3}-\mathrm{N}$ and TP were obtained through $\mathrm{M}-\mathrm{K}$ test and cluster analysis, respectively. Due to the interdependence of multiple factors (land use types, landscape patterns and socioeconomic development), Partial least squares regression (PLSR) was used to quantify the impacts of the influencing factor set on spatiotemporal variation of $\mathrm{NH}_{3}-\mathrm{N}$ and TP concentration in the Huangshui River basin from 2015 to 2018. The importance rankings of the influencing factors on $\mathrm{NH}_{3}-\mathrm{N}$ and $\mathrm{TP}$ were obtained and then the main influencing factors were acquired. The main objectives of this paper are to (1) identify temporal and spatial variation patterns of ammonia nitrogen and total phosphorus in Huangshui River basin with the available monitoring dataset and (2) determine how the temporal and spatial variation of specific water contaminant attributed to multiple factors referred in this study using PLSR. This work can provide theoretical basis and technical support for the control and management of nitrogen and phosphorus pollution in upper reaches of rivers.

\section{Materials and methods}

\section{Study area}

This study was conducted in Huangshui River basin, which rises in the Haibei Tibetan Autonomous Prefecture of Qinghai Province (Fig. 2). Huangshui River

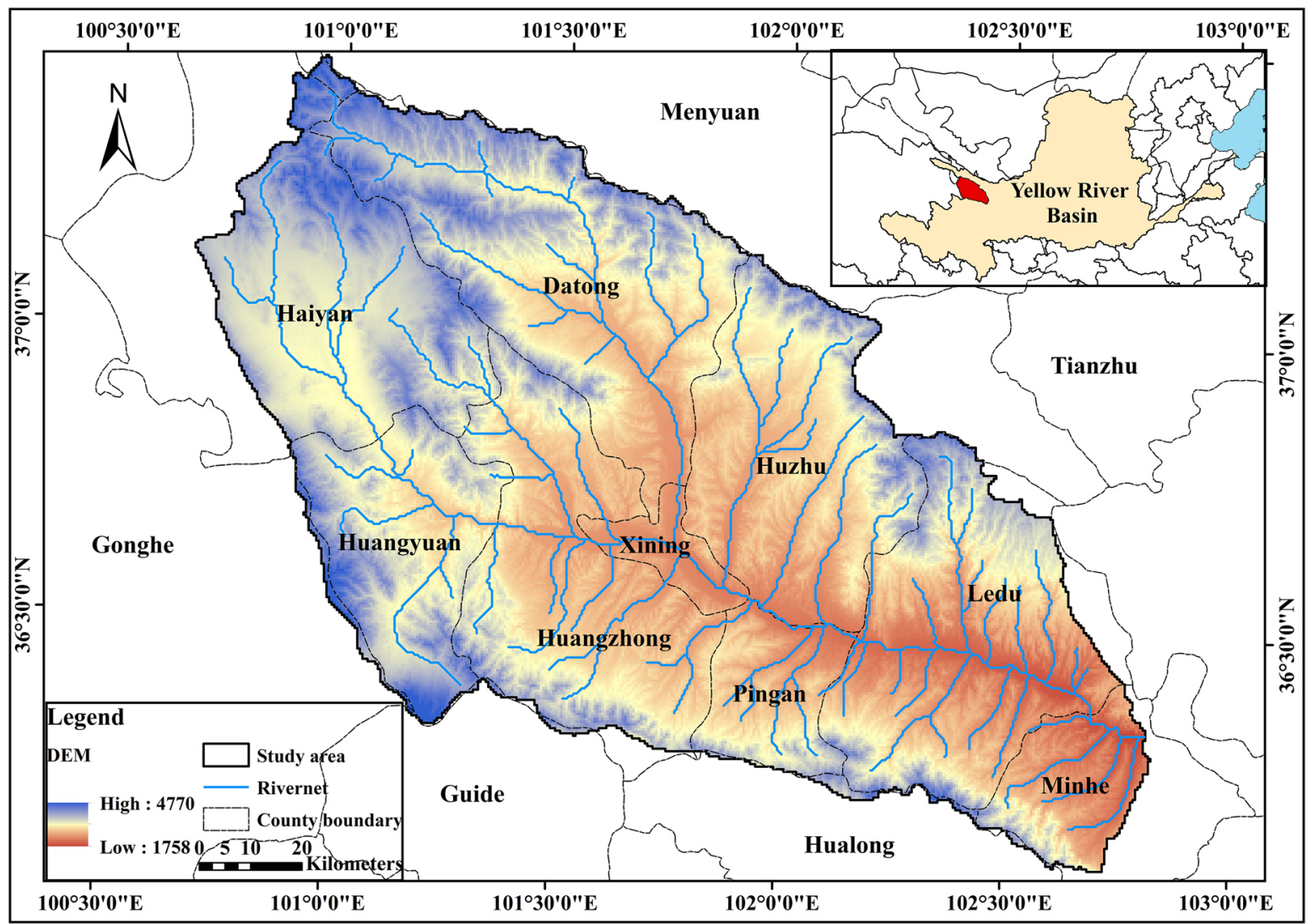

Fig. 2 Location of Huangshui River basin 
is a first-degree tributary of the upper reaches of the Yellow River. The river is located within $36^{\circ} 02^{\prime}$ $\mathrm{E}-37^{\circ} 8^{\prime} \mathrm{E}$ and $100^{\circ} 42^{\prime} \mathrm{N}-103^{\circ} 04^{\prime} \mathrm{N}$, which also lies in the transition zone between the Qinghai-Tibet Plateau and the Loess Plateau. Ecological fragility is the typical feature of this area. The total length of the main stream is $374 \mathrm{~km}$, with a drainage area of $17,733 \mathrm{~km}^{2}$. The study site covers most of Huangshui River basin from the upper reaches of Yellow River to Minhe County, flowing through counties such as Haiyan, Huangyuan, Huangzhong, Datong, Xining, Huzhu, Ping An, Ledu, Minhe. As of 2017, the total population of the Huangshui River Basin was 3.5329 million, accounting for $60.2 \%$ of the total population of Qinghai Province (5.87 million). With the rapid development of Xining urban agglomeration in recent years, the water environment and aquatic ecology of the Huangshui River Basin have been threatened. The main stream length of this region is $278 \mathrm{~km}$ with a drainage area of $15,558 \mathrm{~km}^{2}$, as shown in Fig. 2. The terrain of the region is relative lower in the southeast and higher in the northwestern. The region has high topographic relief (elevation change of $3107 \mathrm{~m}$ from river source to mouth) with complex landform types (Liu et al., 2020). The region experiences an arid and semi-arid continental climate with the mean average precipitation of $381.1 \mathrm{~mm}$ (1960-2017 records) (Yu et al., 2015). The mean average air temperature ranged from 3.1 to $7.9{ }^{\circ} \mathrm{C}$ (1960-2017 records). The mean annual runoff at the Minhe hydrological station (the outlet of the research basin) was approximately 2053 million $\mathrm{m}^{3}$ (1956-2000 records). According to the land use classification results of 2017 , forest was the mainly type of land use, followed by grasslands and cropland, occupying $92.91 \%$ in total.

\section{Materials}

\section{Water contamination}

We collected all water contaminant data and other spatial data from several government agencies (details in the "Water contamination," "Potential controlling factors," and "Spatial data" sections), statistical analysis and PLSR were combined to link them. The water contaminant dataset was supplied by the Department of Ecological Environment of Qinghai Province, China, at monthly intervals from 2015 to 2018 at 13 monitoring sites, as shown in Fig. 3.
Measurements were performed on standard water samples, and all analytical techniques and calculation methods were performed according to the environmental quality standards for surface water (CSEPB, 2002). Five variables, including ammonia nitrogen $\left(\mathrm{NH}_{3}-\mathrm{N}\right)$, total phosphorus (TP), pondus hydrogenii $(\mathrm{pH})$, the dissolved oxygen (DO), and potassium permanganate index $\left(\mathrm{COD}_{\mathrm{Mn}}\right)$ were analyzed in this study. The specific analysis methods for water quality items were presented as follows: $\mathrm{NH}_{3}-\mathrm{N}$, spectrophotometric method with salicylic acid; TP, spectrophotometric method with ammonium molybdate; $\mathrm{pH}$, glass electrode method; DO, electrochemical probe method; $\mathrm{COD}_{\mathrm{Mn}}$, acidic (alkaline) potassium permanganate method.

\section{Potential controlling factors}

Based on previous hypothesis, the spatiotemporal variation of ammonia nitrogen and total phosphorus concentration are affected by six categories of factors. A total of 21 factors (Table 1), which belong to six aforementioned categories, were extracted as potential controlling factors in the statistical analysis. Rainfall-runoff relationship factor (that is runoff coefficient) was calculated based on the monthly outputs of rainfall and runoff from distributed hydrological model (WEP) (He et al., 2019). The land cover maps in 2015 and 2017 were used for characterizing land use type and landscape patterns were analyzed by ArcGIS 10.2 platform and the Fragstats 4.2 software, which were widely used for landscape metrics calculation (McGarigal et al., 2015). The topography data including average slope and HI were obtained by processing dem and slope data through zonal statistics module in ArcGIS 10.2. The basic data of population, livestock, regional GDP, and the added value of the primary, secondary, and tertiary industries in each district or county of the basin have three main sources. They are the National Economic and Social Development Statistical Bulletin of each district or county from 2015 to 2018, the Statistical Yearbook of each district or county from 2016 to 2019 and the China County Statistical Yearbook from 2016 to 2019. The population number, livestock quantity, regional gross product value, primary, secondary, and tertiary industries within each catchment were obtained by weighted average method. The weights were set according to the proportion of the area of 


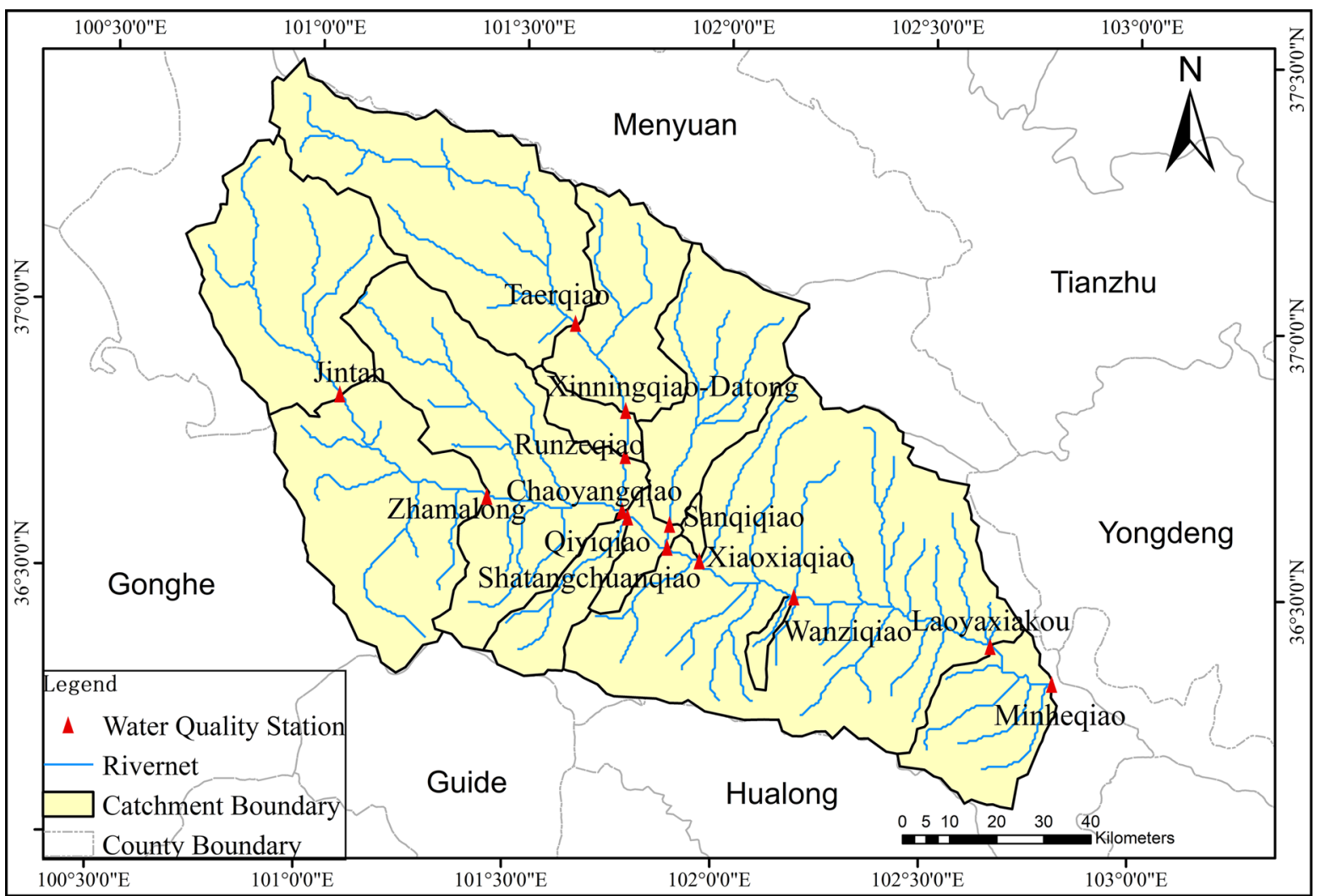

Fig. 3 Study area and the catchments distribution based on water quality monitoring stations

each district or county in each catchment. For the convenience of comparison, livestock quantities of different species were uniformly converted into pig equivalent, and the corresponding conversion coefficients referred to the monograph of Huang et al. (2014). The values of Pop_Den, Liv_Den, PPI, PSI, and PTI in each catchment were calculated accordingly.

\section{Spatial data}

For the basin scale, the boundary of each catchment was depicted by means of the DEM data in the ArcGIS, and each water quality monitoring station was deemed to be the outlet of the corresponding catchments (Fig. 3). Digital elevation model (DEM) data used in this study derived from National Geomatic Centre of China with resolution of $90 \mathrm{~m} * 90 \mathrm{~m}$. Land cover map of the basin in 2015 derived from Tsinghua University (http://data. ess.tsinghua.edu.cn/), and that in 2017 was from Department of Natural Resources of Qinghai Province, China.
Methods

In this paper, an influencing factor set which includes the rainfall-runoff relationship, basic physical and chemical parameters of water quality, land use types, landscape patterns, topography, and socioeconomic development was constructed. Based on Matlab algorithms, the temporal mutation characteristics of $\mathrm{NH}_{3}-\mathrm{N}$ and $\mathrm{TP}$ in each catchment were obtained through $\mathrm{M}-\mathrm{K}$ test. Moreover, the spatial clustering characteristics of $\mathrm{NH}_{3}-\mathrm{N}$ and TP in catchments were obtained by cluster analysis. On this basis, PLSR was used to quantify the complex interdependencies between the influencing factor set, and spatiotemporal variation of ammonia nitrogen and total phosphorus concentration in the basin. From the perspectives of temporal and spatial variation, the importance rankings of the influencing factors on $\mathrm{NH}_{3}-\mathrm{N}$ and $\mathrm{TP}$ were obtained and the main controlling factors were acquired accordingly, which lay the foundation for 
Table 1 Categories, abbreviation, and description of the selected factors in the influencing factor set

\begin{tabular}{|c|c|c|c|}
\hline Categories & Factors & Abbreviation & Description \\
\hline Rainfall-runoff relationship & Runoff coefficient (dimensionless) & $\mathrm{RC}$ & $\begin{array}{l}\text { Annual runoff at the outlet of each catch- } \\
\text { ment/annual rainfall above the outlet of } \\
\text { each catchment }\end{array}$ \\
\hline \multirow{3}{*}{$\begin{array}{l}\text { Basic physical and chemi- } \\
\text { cal parameters of water } \\
\text { quality }\end{array}$} & $\mathrm{pH}$ & l & l \\
\hline & DO & / & l \\
\hline & $\mathrm{COD}_{\mathrm{Mn}}$ & l & l \\
\hline \multirow[t]{5}{*}{ Land use types } & $\begin{array}{l}\text { Proportion of forest area }(2015,2017) \\
\text { (dimensionless) }\end{array}$ & PFA & The ratio of forest area in a catchment \\
\hline & $\begin{array}{l}\text { Proportion of grassland area (dimension- } \\
\text { less) }\end{array}$ & PGA & The ratio of grassland area in a catchment \\
\hline & Proportion of water area (dimensionless) & PWA & The ratio of water area in a catchment \\
\hline & $\begin{array}{l}\text { Proportion of cropland area (dimension- } \\
\text { less) }\end{array}$ & PCA & The ratio of cropland area in a catchment \\
\hline & $\begin{array}{l}\text { Proportion of impervious area (dimen- } \\
\text { sionless) }\end{array}$ & PIA & The ratio of impervious area in a catchment \\
\hline \multirow[t]{4}{*}{ Landscape patterns } & Patch density & PD & / \\
\hline & Landscape shape index & LSI & / \\
\hline & Patch cohesion index & COHESION & / \\
\hline & Shannon's diversity index & SHDI & / \\
\hline \multirow[t]{2}{*}{ Topography } & Average slope $\left(^{\circ}\right)$ & l & Average slope gradient of a catchment \\
\hline & $\mathrm{HI}$ & l & $\begin{array}{l}\mathrm{HI}=(\text { Hmean-Hmin }) /(\text { Hmax-Hmin }) \text { where } \\
\text { Hmean is the mean elevation of the catch- } \\
\text { ment }\end{array}$ \\
\hline \multirow[t]{6}{*}{ Socioeconomic development } & Population density $\left(\right.$ person $\left.\times\left(\mathrm{km}^{2}\right)-1\right)$ & Pop_Den & Population per unit of catchment area \\
\hline & Livestock density $\left(\right.$ head $\left.\times\left(\mathrm{km}^{2}\right)-1\right)$ & Liv_Den & $\begin{array}{l}\text { Number of livestock per unit of catchment } \\
\text { area }\end{array}$ \\
\hline & $\begin{array}{l}\text { Gross regional domestic product (ten } \\
\text { thousand yuan) }\end{array}$ & GRDP & l \\
\hline & $\begin{array}{l}\text { Proportion of primary industry (dimen- } \\
\text { sionless) }\end{array}$ & PPI & $\begin{array}{l}\text { The ratio of the added value of the primary } \\
\text { industry to the regional GDP in a catch- } \\
\text { ment }\end{array}$ \\
\hline & $\begin{array}{l}\text { Proportion of secondary industry (dimen- } \\
\text { sionless) }\end{array}$ & PSI & $\begin{array}{l}\text { The ratio of the added value of the second- } \\
\text { ary industry to the regional GDP in a } \\
\text { catchment }\end{array}$ \\
\hline & $\begin{array}{l}\text { Proportion of tertiary industry (dimen- } \\
\text { sionless) }\end{array}$ & PTI & $\begin{array}{l}\text { The ratio of the added value of the tertiary } \\
\text { industry to the regional GDP in a catch- } \\
\text { ment }\end{array}$ \\
\hline
\end{tabular}

the accurate attribution of the temporal and spatial variation of $\mathrm{NH}_{3}-\mathrm{N}$ and TP (Fig. 4).

\section{$M-K$ test}

The Mann-Kendall test, which is a robust and nonparametric test method, was used to diagnose the temporal trends of water quality parameters (Buendia et al., 2016; Fathian et al., 2016; Li et al., 2018). In this study, it was applied to analyze the temporal mutation characteristics of concentration of $\mathrm{NH}_{3}-\mathrm{N}$ and TP at each monitoring station through Matlab algorithm. Through UF statistics and UB statistics, trend and mutation time of the variable can be obtained. If UF statistics $>0(<0)$, the sequence of $\mathrm{NH}_{3}-\mathrm{N}$ or TP is on the rise (down) trend, when it exceeds the critical line $(p<0.05)$, it indicates the rise or fall of the trend is significant. 


\section{Spatiotemporal Variation of Nitrogen and Phosphorus and Its Main Influencing} Factors in Huangshui River Basin

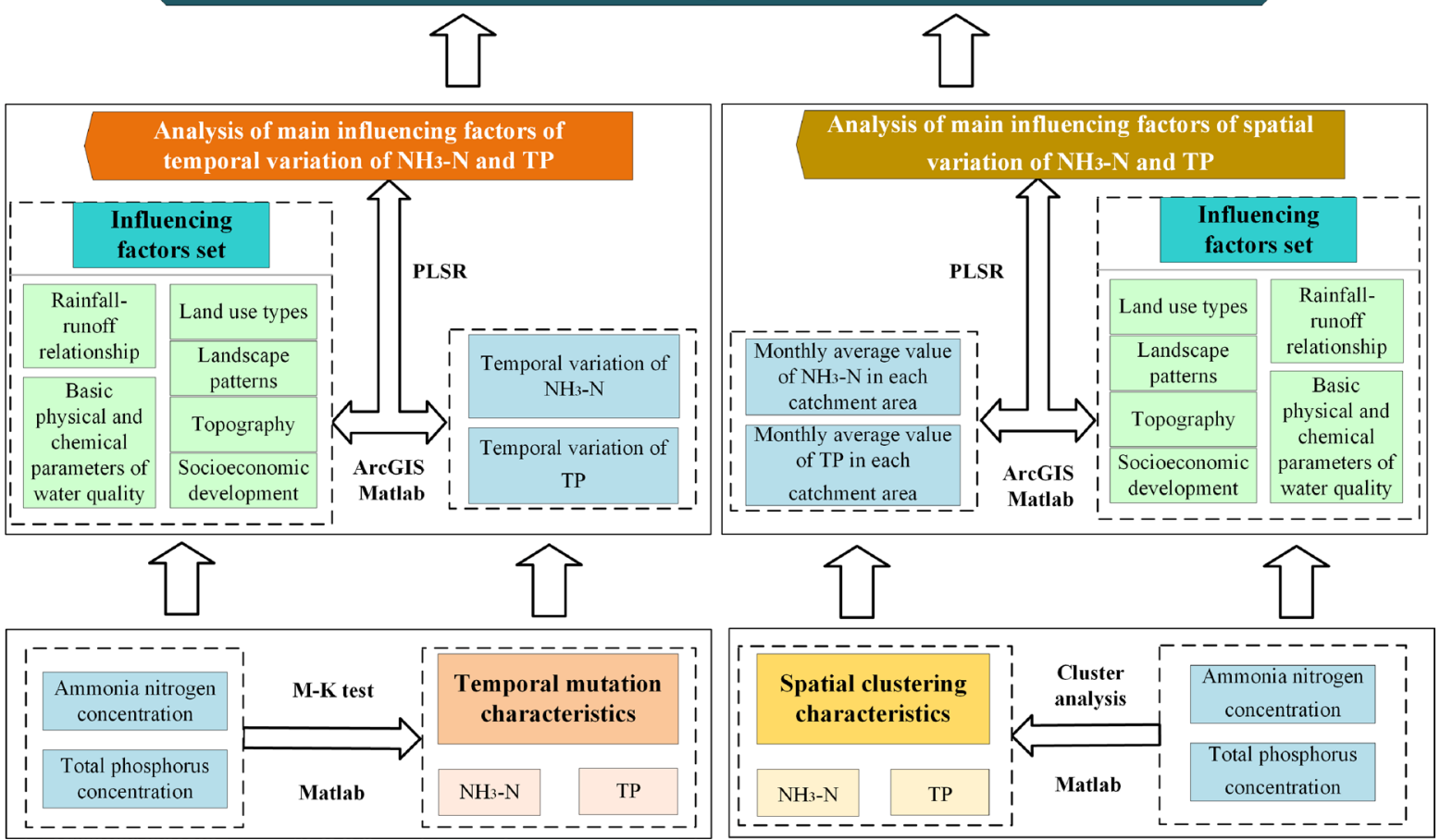

Fig. 4 Research workflow of spatiotemporal variation of nitrogen and phosphorus concentration in Huangshui River basin and identification of main controlling factors

\section{Cluster analysis}

CA is a reduction statistical method which is commonly used to classify objects into groups according to their nearness. The objects are categorized by linking inter-sample commonalities so that the outcome demonstrates the general similarity of the components in a given set of data (Razmkhah et al., 2010). The most common approach is hierarchical agglomerative cluster analysis, which build the solution by initially assigning each document to its own cluster and then repeatedly selecting and merging pairs of clusters, to obtain a single all-inclusive cluster (Al-Murairi et al., 2014; Zhao $\&$ Karypis, 2005). The output of this cluster process is a dendrogram, and the similarities and dissimilarities are quantified through Euclidean distance measurement. In this study, hierarchical agglomerative cluster analysis was carried out to ascertain the multivariate similarity between different water quality monitoring stations based on the time series of concentration of $\mathrm{NH}_{3}-\mathrm{N}$ and TP in the Huangshui River basin. The CA was performed through programming and calculation on Matlab platform.

\section{PLSR}

The PLSR is an extension of multiple regression analysis which the effects of linear combinations of several predictors on a response variable (or multiple response variables) are analyzed. PLSR was developed for econometric modeling of multivariate time series and later was applied in chemometrics (Wold, 1995) and hyperspectral remote sensing (Min \& Lee, 2005). PLSR can handle highly correlated variables on the principle of variable compression and is particularly suitable for cases in which the number of observations is less than the possible variables (Carrascal et al., 2009; Luedeling \& Gassner, 2012). Mathematically, PLSR is achieved by maximizing the covariance between $y$ and all possible linear functions of $\mathrm{x}$. It is often called as the "better PCA" as it often gives improved prediction results (Luedeling \& Gassner, 2012). 
A PLSR model for ammonia nitrogen $\left(\mathrm{NH}_{3}-\mathrm{N}\right)$ and total phosphorus (TP) was established respectively to identify the main influencing factors temporally and spatially in order to obtain the attribution of spatiotemporal variation of $\mathrm{NH}_{3}-\mathrm{N}$ and TP. Before PLSR analyses, predictors were centered and scaled to unit variance to give them the same relative importance. The percentage of variance explained for the response variables, the cross-validated root mean squared error (RMSE), which is the difference between the predicted and observed values of each individual pass. The predictor coefficients (magnitude and direction) were used to examine the influence of predictors on responses. The PLSR was performed using Matlab algorithm.

\section{Results}

Temporal mutation characteristics of $\mathrm{NH}_{3}-\mathrm{N}$ and TP

Less than a quarter of the 13 water quality monitoring stations showed a significant decline in the concentration of $\mathrm{NH}_{3}-\mathrm{N}$ and TP. As shown in Figs. 5 and 6, Xinningqiao-Datong, Minheqiao catchment showed a significant decline of $\mathrm{NH}_{3}-\mathrm{N}$ concentration and Runzeqiao, Xiaoxiaqiao, and Minheqiao exhibited a significant decline of TP concentration. As listed in Table S1 (Supplement Materials), the number of mutations of $\mathrm{NH}_{3}-\mathrm{N}$ concentration in the middle reaches of the Huangshui River basin was generally higher than that in the upper and lower reaches. Specifically, the numbers of mutations of $\mathrm{NH}_{3}-\mathrm{N}$ in Runzeqiao, Chaoyangqiao, Sanqiqiao, and Shatangchuanqiao catchments were all larger than 4 . The numbers of mutations of $\mathrm{NH}_{3}-\mathrm{N}$ of the catchments in the upstream section except Jintan were less than 3 , and the numbers of mutations of $\mathrm{NH}_{3}-\mathrm{N}$ in catchments of the downstream section were all less than 3 . The numbers of mutations of TP in 11 catchments out of 13 catchments in the basin were less than that of $\mathrm{NH}_{3}-\mathrm{N}$. Specifically, in the middle reaches, the numbers of mutations of TP in Runzeqiao and Chaoyangqiao catchments were equal or larger than 3. Moreover, in the upper reaches, the numbers of mutations of TP in Jintan and Taerqiao catchments were equal or larger than 3. However, the numbers of mutations of $\mathrm{TP}$ in catchments of the lower reaches were less.
Spatial cluster characteristics

The results of cluster analysis of $\mathrm{NH}_{3}-\mathrm{N}$ showed that Jintan, Zhamalong, and Taerqiao catchments at the upstream section belonged to entire qualified class (subject to Class III standards for surface water bodies in GB3838-2002) (CSEPB, 2002). XinningqiaoDatong, Runzeqiao, and Minheqiao catchments belonged to basic compliance class. Wanziqiao and Laoyaxiakou catchments belonged to basic excess class. Other catchments belonged to the different categories, respectively. All of them were sectional excess categories, with the different length of the excessing period (Fig. 7, Table 2).

The results of cluster analysis of TP showed that Jintan, Zhamalong, and Taerqiao catchment at the upstream section belonged to nearly entire qualified class (subject to Class III standards for surface water bodies in GB3838-2002) (CSEPB, 2002). Runzeqiao, Sanqiqiao and Minheqiao catchments belonged to basic compliance class. Wanziqiao and Laoyaxiakou catchments fall into sectional excess class. Xiaoxiaqiao catchment pertain to basic excess class. Other catchments belonged to the different categories respectively, all of which were sectional excess categories, with the different length of the excessing period (Fig. 8, Table 3).

In comparison, the cluster analysis results of $\mathrm{NH}_{3}-\mathrm{N}$ and TP of each catchment were similar.

There were slightly differences in the basic compliance class of the two (Group 2). The basic excess class of $\mathrm{NH}_{3}-\mathrm{N}$ was different from the sectional excess class of TP in Group.5. This may be due to the differences in the types of pollutants and the characteristics of the catchment.

Attribution analysis of temporal and spatial variation

\section{Attribution analysis of temporal variation of concentration of $\mathrm{NH}_{3}-\mathrm{N}$ and $\mathrm{TP}$}

The temporal variation characteristics of $\mathrm{NH}_{3}-\mathrm{N}$ in 7 catchments out of 13 catchments were mainly affected by three factors: PWA, PIA, PPI. The importance rankings of these three factors were different among catchments. The temporal variation characteristics of $\mathrm{NH}_{3}-\mathrm{N}$ in other catchments were significantly affected by RC, PSI, PTI, SHDI, and PGA factors (Tables 4 and 5). 

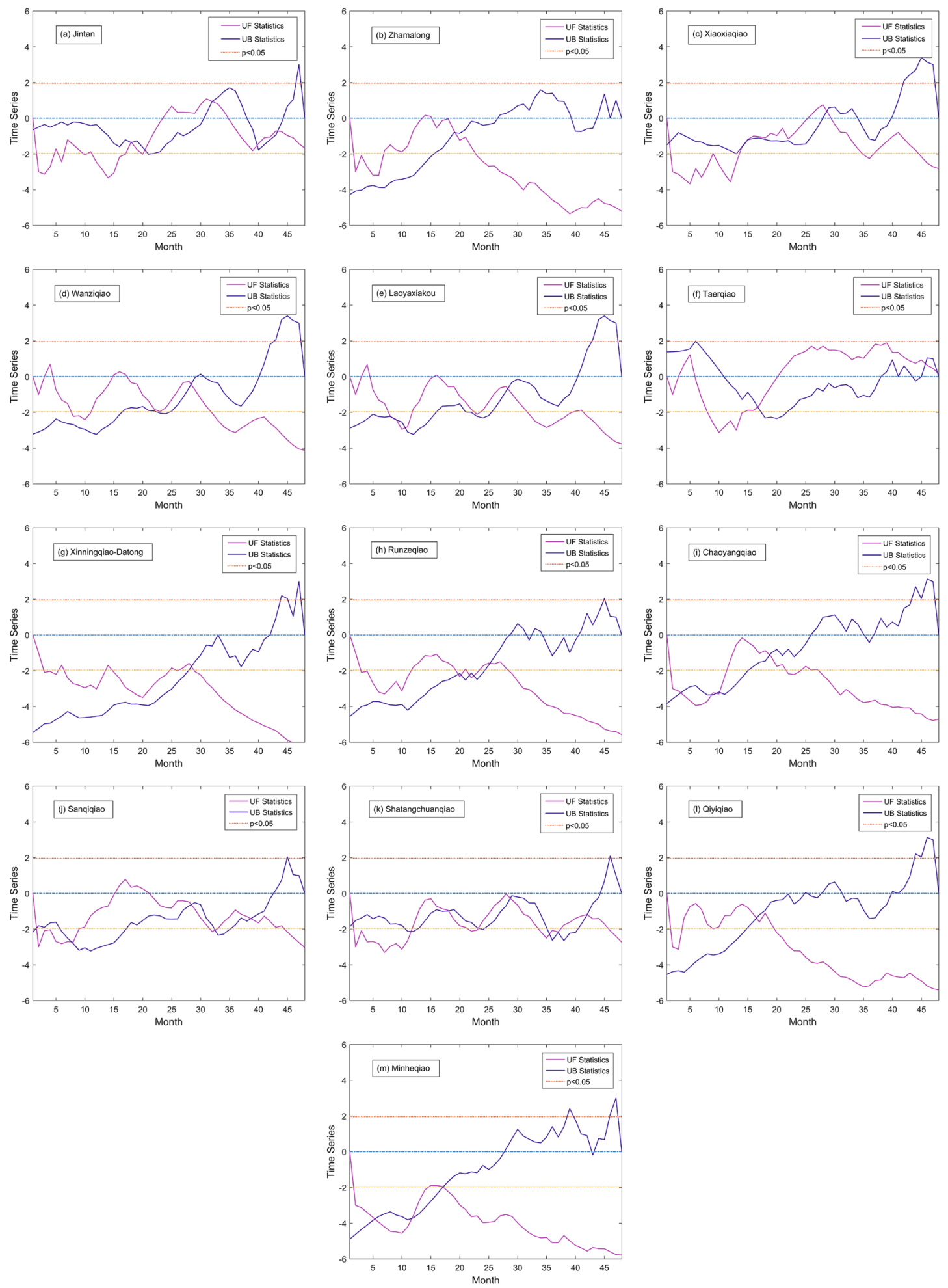

Fig. 5 Temporal mutation characteristics of $\mathrm{NH}_{3}-\mathrm{N}$ in each catchment based on $\mathrm{M}-\mathrm{K}$ test 

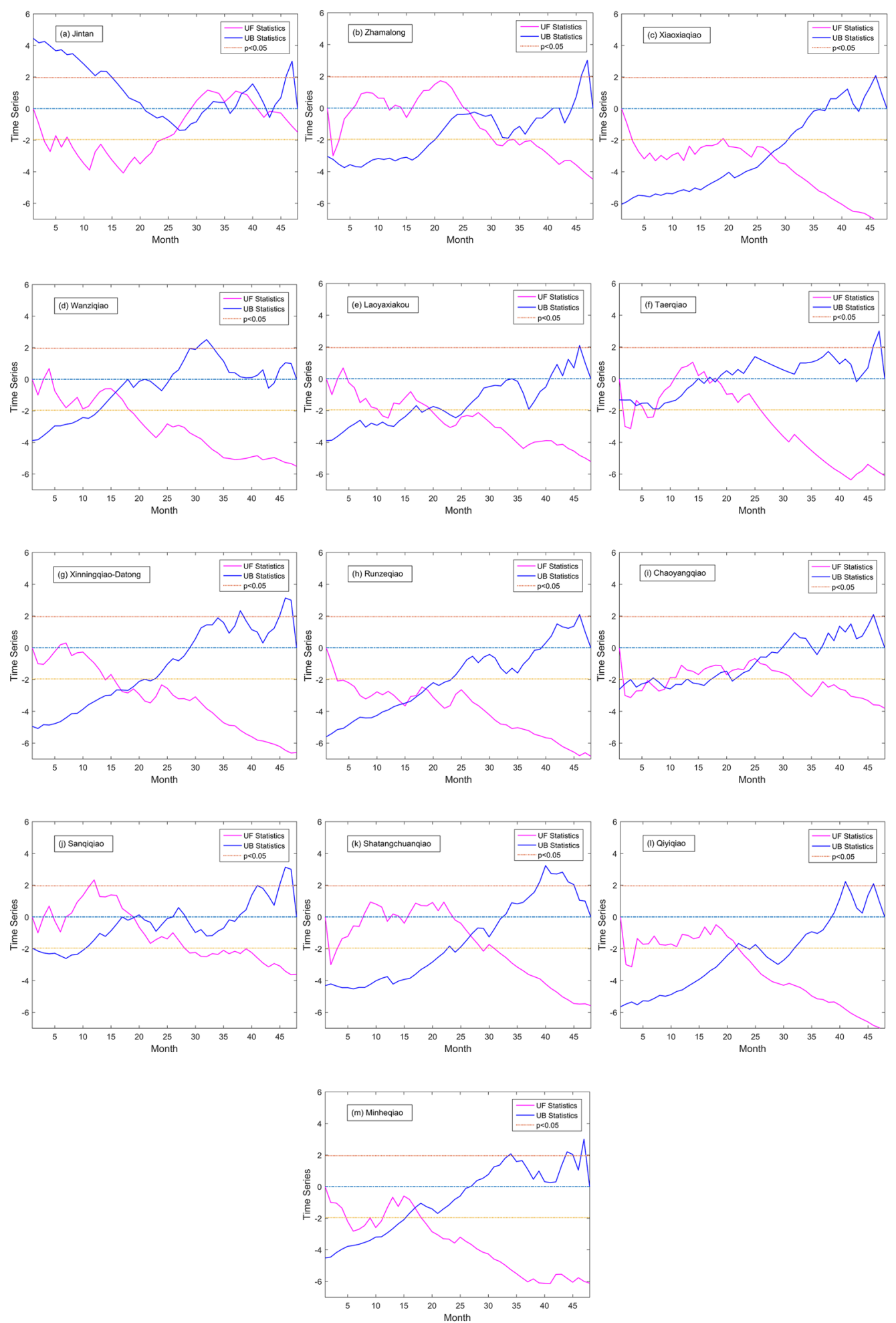

Fig. 6 Temporal mutation characteristics of TP in each catchment based on M-K test 
Fig. 7 Dendrogram of cluster analysis of $\mathrm{NH}_{3}-\mathrm{N}$ at different water quality monitoring stations. Z1Z13 represent the number of catchments controlled by the water quality monitoring station

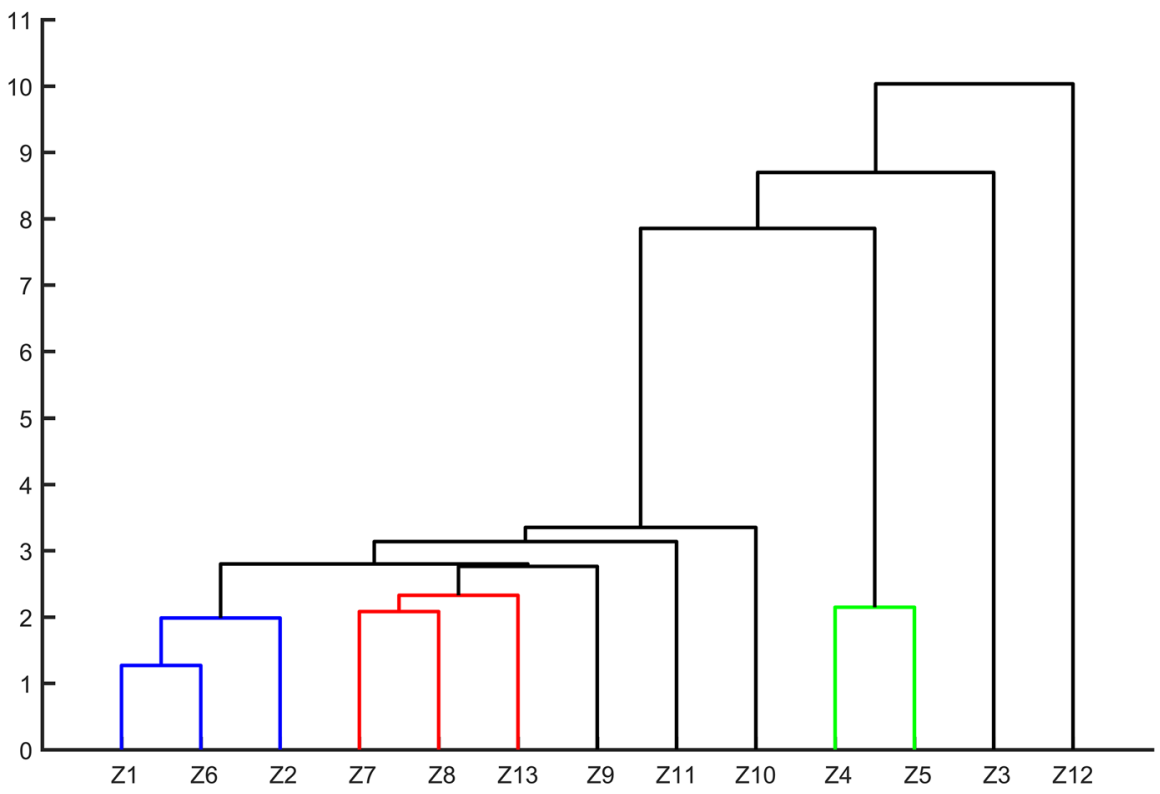

\section{Discussion}

The temporal variation characteristics of TP in 8 catchments out of 13 catchments were mainly affected by three factors: PWA, PIA, PPI. The importance rankings of the three factors were different in different catchments. The temporal variation characteristics of TP in other catchments were significantly affected by PSI, PTI, PCA, PGA and RC factors (Table S2, Table 6).

\section{Attribution analysis of spatial variation of concentration of $\mathrm{NH}_{3}-\mathrm{N}$ and $\mathrm{TP}$}

As listed in Table 7, the spatial variation characteristics of $\mathrm{NH}_{3}-\mathrm{N}$ in the basin were mainly affected by PWA, PSI and HI. Besides, the spatial variation characteristics of TP in the basin were significantly influenced by PWA, PSI and PTI, as shown in Table 8.
Analysis of main controlling factors of temporal variation of $\mathrm{NH}_{3}-\mathrm{N}$ and $\mathrm{TP}$

The temporal variation of $\mathrm{NH}_{3}-\mathrm{N}$ and $\mathrm{TP}$ in Xiaoxiaqiao, Runzeqiao, Sanqiqiao, Shatangchuanqiao, Qiyiqiao, Laoyaxiakou catchment in Huangshui Basin were mainly influenced by factors of PWA, PIA, and PPI. These catchment areas are located in the middle reaches of Huangshui River except Laoyaxiakou. The average concentration of $\mathrm{NH}_{3}-\mathrm{N}$ and TP in this kind of catchment area was relatively high, which may be related to the higher population density (greater than $123 \mathrm{p} / \mathrm{km}^{2}$ ), which was similar to the relevant studies (Alvarez-Cobelas et al., 2008; Wang et al., 2019; Cui et al., 2020). Two thirds of the abovementioned catchments were found with relatively high value
Table 2 Summary of cluster analysis results of $\mathrm{NH}_{3}-\mathrm{N}$ in each catchment

\begin{tabular}{llll}
\hline Serial number & $\begin{array}{l}\text { Abbreviation of } \\
\text { catchments }\end{array}$ & Category & Name of the catchment \\
\hline $\begin{array}{l}\text { Group.1 } \\
\text { Group.2 }\end{array}$ & $\mathrm{Z1,Z6, \textrm {Z } 2}$ & $\begin{array}{l}\text { Entire qualified class } \\
\text { Z7, Z8, Z13 }\end{array}$ & $\begin{array}{l}\text { Jasic compliance class } \\
\text { Xinningqiao-Datong, } \\
\text { Runzeqiao, Minheqiao }\end{array}$ \\
Group.3 & $\mathrm{Z} 9$ & Sectional excess class & Chaoyangqiao \\
Group.4 & $\mathrm{Z} 11$ & Sectional excess class & Shatangchuanqiao \\
Group.5 & $\mathrm{Z} 10$ & Sectional excess class & Sanqiqiao \\
Group.6 & $\mathrm{Z} 4, \mathrm{Z} 5$ & Basic excess class & Wanziqiao, Laoyaxiakou \\
Group.7 & $\mathrm{Z} 3$ & Sectional excess class & Xiaoxiaqiao \\
Group.8 & $\mathrm{Z} 12$ & Sectional excess class & Qiyiqiao \\
\hline
\end{tabular}


Fig. 8 Dendrogram of cluster analysis of TP at different water quality monitoring stations. Z1Z13 represent the number of catchments controlled by the water quality monitoring station

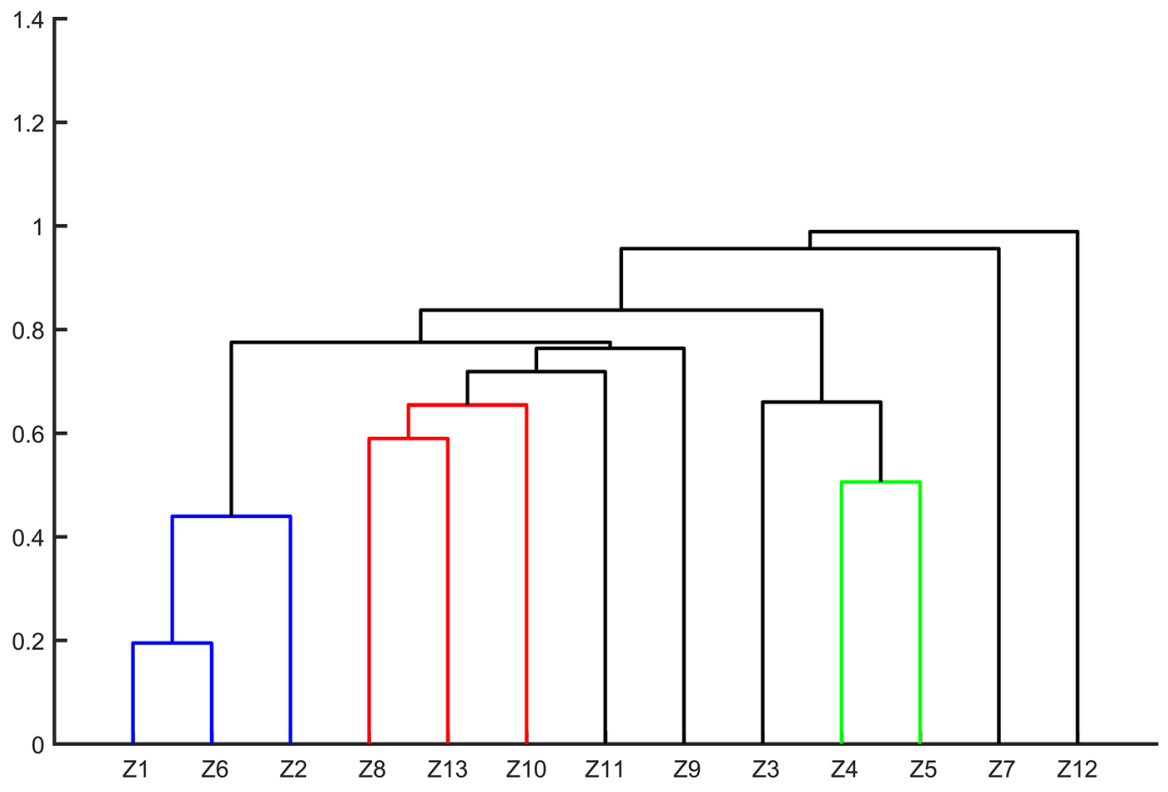

of PIA (more than 0.05), and low values of the elevations. The significant influences of PWA and PIA on the temporal change of $\mathrm{NH}_{3}-\mathrm{N}$ and TP in these catchments reflected that the land use type was the main factor affecting the $\mathrm{NH}_{3}-\mathrm{N}$ and TP concentration in the middle reaches of the Huangshui watershed. Because land use types can conceivably affect the runoff processes which carry anthropogenic substances such as nutrients into rivers; therefore, certain land use types can influence on water contaminant concentrations (Zhou et al., 2012).

Pellerin et al. (2004) found that the nitrogen export through streams may be related with the ratio of wetland areas in the catchments, which promotes nitrogen retention and volatilization. $\mathrm{Li}$ et al. (2020) concluded that the ratio of urban areas, and the ratio of forest areas were major influential indicators that affected TN and TP in river water. Jabbar and Grote
(2019) hold the view that water quality parameters $\mathrm{P}$ were also correlated with the percentage of urban land. Similarly, our research found that the temporal variations of ammonia nitrogen and total phosphorus were significantly influenced by PWA and PIA. The PPI of Xiaoxiaqiao and Sanqiqiao catchment in the upper reaches were higher (greater than 0.17) and the PPI of the remaining catchments were all less than 0.09. It was shown that PPI with too high or low values may make it the main controlling factor for the temporal change of $\mathrm{NH}_{3}-\mathrm{N}$ and TP.

The temporal change of TP in Xinningqiao-Datong catchment was significantly affected by PPI and PIA, which may be related to the higher PPI (close to 0.16) and middle PIA (about 0.06). Moreover, the temporal variation of $\mathrm{NH}_{3}-\mathrm{N}$ in Chaoyangqiao catchment was also mainly affected by three factors: PWA, PIA, and
Table 3 Summary of cluster analysis results of $\mathrm{TP}$ in each catchment

\begin{tabular}{|c|c|c|c|}
\hline Serial number & $\begin{array}{l}\text { Abbreviation } \\
\text { of catchments }\end{array}$ & Category & Name of the catchment \\
\hline Group.1 & $\mathrm{Z1,Z6,Z2}$ & Nearly entire qualified class & Jintan, Taerqiao, Zhamalong \\
\hline Group.2 & $\mathrm{Z} 8, \mathrm{Z13}, \mathrm{Z} 10$ & Basic compliance class & Runzeqiao, Minheqiao, Sanqiqiao \\
\hline Group.3 & Z9 & Sectional excess class & Chaoyangqiao \\
\hline Group.4 & Z11 & Sectional excess class & Shatangchuanqiao \\
\hline Group.5 & $\mathrm{Z7}$ & Sectional excess class & Xinningqiao-Datong \\
\hline Group.6 & $\mathrm{Z} 4, \mathrm{Z5}$ & Sectional excess class & Wanziqiao, Laoyaxiakou \\
\hline Group.7 & $\mathrm{Z3}$ & Basic excess class & Xiaoxiaqiao \\
\hline Group.8 & $\mathrm{Z} 12$ & Sectional excess class & Qiyiqiao \\
\hline
\end{tabular}




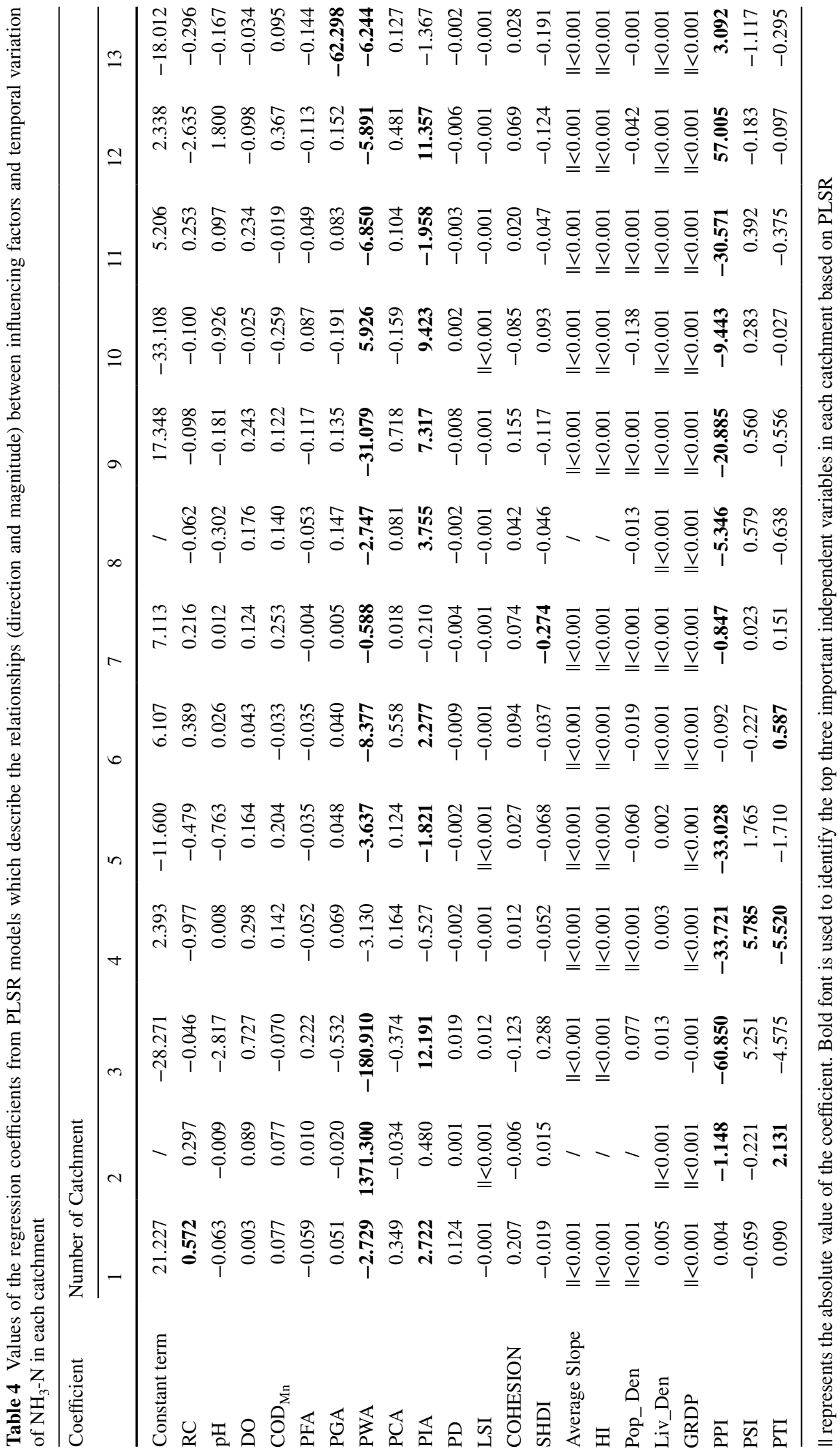


Table 5 Results from the PLSR models for temporal variation of $\mathrm{NH}_{3}-\mathrm{N}$ in each catchment

\begin{tabular}{llllllll}
\hline $\begin{array}{l}\text { Number of } \\
\text { Catchment }\end{array}$ & Name & $\begin{array}{l}\text { Mean concen- } \\
\text { tration }(\mathrm{mg} / \mathrm{L})\end{array}$ & $\mathrm{R}^{2}$ & \multicolumn{2}{l}{ RMSE } & \multicolumn{2}{l}{$\begin{array}{l}\text { Significant Factors of } \\
\text { Influence }\end{array}$} \\
\hline 1 & Jintan & 0.19 & 0.15 & 0.91 & PWA & PIA & RC \\
2 & Zhamalong & 0.27 & 0.54 & 0.67 & PWA & PTI & PPI \\
3 & Xiaoxiaqiao & 1.88 & 0.30 & 0.83 & PWA & PPI & PIA \\
4 & Wanziqiao & 1.73 & 0.23 & 0.87 & PPI & PSI & PTI \\
5 & Laoyaxiakou & 1.55 & 0.17 & 0.90 & PPI & PWA & PIA \\
6 & Taerqiao & 0.11 & 0.26 & 0.85 & PWA & P0.00IA & PTI \\
7 & Xinningqiao-Datong & 0.48 & 0.61 & 0.62 & PPI & PWA & SHDI \\
8 & Runzeqiao & 0.54 & 0.53 & 0.68 & PPI & PIA & PWA \\
9 & Chaoyangqiao & 0.73 & 0.42 & 0.76 & PWA & PPI & PIA \\
10 & Sanqiqiao & 0.71 & 0.29 & 0.84 & PPI & PIA & PWA \\
11 & Shatangchuanqiao & 0.74 & 0.31 & 0.82 & PPI & PWA & PIA \\
12 & Qiyiqiao & 1.38 & 0.46 & 0.73 & PPI & PIA & PWA \\
13 & Minheqiao & 0.55 & 0.37 & 0.78 & PGA & PWA & PPI \\
\hline
\end{tabular}

PPI. While the temporal change of TP was affected by RC obviously, which may be related to the low degree of human development and the distribution of temperate deciduous broad-leaved forest in the northwest of the catchment.

The temporal change of $\mathrm{NH}_{3}-\mathrm{N}$ in Jintan catchment was significantly affected by PWA, PIA, and RC. The Jintan catchment was located in the upper reaches of the Huangshui River with low average concentration of $\mathrm{NH}_{3}-\mathrm{N}$. It may due to its lowest population density and livestock density among all the catchments. Meanwhile, the land use type of this catchment was mainly grassland and woodland $(>0.85)$, and the impervious ground area only accounted for a small proportion $(<0.01)$. This is in accord with that agriculture land and urban land were negatively correlated with surface water quality, whereas forested land, water area, and grassland were positively correlated with water quality (Chen et al., 2016; Lee et al., 2020; Xu et al., 2019a). The PPI was relatively high $(>0.09)$, and the secondary industry was underdeveloped (PSI was approximately equal 0.37 ). In addition, the temporal change of $\mathrm{NH}_{3}-\mathrm{N}$ was obviously affected by the runoff coefficient, which may be closely related to the low degree of socioeconomic development in this catchment. The temporal change of TP in Jintan
Table 6 Results from the PLSR models for temporal variation of TP in each catchment

\begin{tabular}{llllllll}
\hline $\begin{array}{l}\text { Number of } \\
\text { catchment }\end{array}$ & Name & $\begin{array}{l}\text { Mean concen- } \\
\text { tration }(\mathrm{mg} / \mathrm{L})\end{array}$ & $R^{2}$ & RMSE & \multicolumn{3}{l}{$\begin{array}{l}\text { Significant factors of } \\
\text { influence }\end{array}$} \\
\hline 1 & Jintan & 0.02 & 0.34 & 0.81 & PWA & PIA & PPI \\
2 & Zhamalong & 0.07 & 0.65 & 0.58 & PWA & PTI & PIA \\
3 & Xiaoxiaqiao & 0.22 & 0.58 & 0.64 & PWA & PPI & PIA \\
4 & Wanziqiao & 0.23 & 0.44 & 0.74 & PPI & PTI & PSI \\
5 & Laoyaxiakou & 0.21 & 0.24 & 0.86 & PPI & PWA & PIA \\
6 & Taerqiao & 0.03 & 0.44 & 0.74 & PWA & PIA & PCA \\
7 & Xinningqiao-Datong & 0.14 & 0.91 & 0.29 & PWA & PIA & PPI \\
8 & Runzeqiao & 0.13 & 0.58 & 0.64 & PIA & PWA & PPI \\
9 & Chaoyangqiao & 0.18 & 0.25 & 0.86 & PWA & PIA & RC \\
10 & Sanqiqiao & 0.16 & 0.29 & 0.84 & PPI & PIA & PWA \\
11 & Shatangchuanqiao & 0.15 & 0.51 & 0.69 & PPI & PWA & PIA \\
12 & Qiyiqiao & 0.17 & 0.46 & 0.73 & PIA & PPI & PWA \\
13 & Minheqiao & 0.13 & 0.47 & 0.72 & PGA & PPI & PTI \\
\hline
\end{tabular}


Table 7 Values of the regression coefficients and other results from PLSR models which describe the relationships (direction and magnitude) between influencing factors and spatial variation of $\mathrm{NH}_{3}-\mathrm{N}$ of the whole basin

\begin{tabular}{lrrr}
\hline Influencing factors & Coefficient & $R^{2}$ & RMSE \\
\hline Constant term & -3.843 & 0.98 & 0.15 \\
RC & 0.031 & & \\
pH & 0.078 & & \\
DO & -0.266 & & \\
COD & 1.003 & & \\
PFA & 0.022 & \\
PGA & 0.390 & \\
PWA & 95.193 & & \\
PCA & -0.399 & & \\
PIA & 0.307 & \\
PD & 0.090 & \\
LSI & 0.006 & \\
COHESION & -0.068 & \\
SHDI & 0.168 & \\
Average Slope & -0.001 & \\
HI & 1.298 & \\
Pop_Den & -0.001 & \\
Liv_Den & $\|<0.001$ & \\
GRDP & $\|<0.001$ & \\
PPI & -1.017 & \\
PSI & -1.445 & \\
PTI & 1.054 & \\
\hline & & \\
& & \\
\end{tabular}

|| represents the absolute value of the coefficient

catchment was significantly affected by PWA, PIA and PPI, followed by PCA, COHESION and RC, which indicated that agricultural non-point source pollution in the catchment may have a relatively large contribution to the total phosphorus load.

The temporal variations of $\mathrm{NH}_{3}-\mathrm{N}$ and $\mathrm{TP}$ in Zhamalong and Wanziqiao catchments were significantly affected by PTI, of which Wanziqiao catchment was also significantly affected by PSI. This may be related to the small value of average PTI of Zhamalong catchment $(<0.3)$, and the larger value of the sum of PTI and PSI in Wanziqiao catchment $(>0.9)$. The results were similar with (Xu et al., 2019 b), which found wastewater from sewage outfalls was the largest contributor (26.2\%) to AN pollution in dry seasons in Huaihe River basin.

The temporal change of $\mathrm{NH}_{3}-\mathrm{N}$ in the Taerqiao catchment and the temporal change of TP in the Minheqiao catchment were both significantly affected
Table 8 Values of the regression coefficients and other results from PLSR models which describe the relationships (direction and magnitude) between influencing factors and spatial variation of TP of the whole basin

\begin{tabular}{|c|c|c|c|}
\hline Influencing factors & Coefficient & $R^{2}$ & RMSE \\
\hline Constant term & -2.596 & 0.99 & 0.07 \\
\hline $\mathrm{RC}$ & -0.096 & & \\
\hline $\mathrm{pH}$ & -0.045 & & \\
\hline DO & -0.037 & & \\
\hline $\mathrm{COD}_{\mathrm{Mn}}$ & 0.080 & & \\
\hline PFA & 0.111 & & \\
\hline PGA & -0.017 & & \\
\hline PWA & -3.895 & & \\
\hline PCA & 0.028 & & \\
\hline PIA & 0.030 & & \\
\hline PD & 0.007 & & \\
\hline LSI & $\|<0.001$ & & \\
\hline COHESION & -0.023 & & \\
\hline SHDI & 0.018 & & \\
\hline Average Slope & -0.001 & & \\
\hline $\mathrm{HI}$ & 0.053 & & \\
\hline Pop_Den & $\|<0.001$ & & \\
\hline Liv_Den & $\|<0.001$ & & \\
\hline GRDP & $\|<0.001$ & & \\
\hline PPI & $-0.113(0)$ & & \\
\hline PSI & & & -0.153 \\
\hline PTI & & & $0.113(2)$ \\
\hline
\end{tabular}

II represents the absolute value of the coefficient

by PTI, which indicated that socioeconomic activities, especially $\mathrm{NH}_{3}-\mathrm{N}$ and TP discharge from the tertiary industry, have become a serious problem for the entire Huangshui basin. Meanwhile, the temporal change of TP in the Taerqiao catchment was obviously affected by PCA, which may be related to the lower average PCA (close to 0.16) in the catchment. The temporal variation of TP in the Minheqiao catchment was obviously affected by PGA which maybe related with the lower mean value of PGA.

Analysis of main controlling factors of spatial variation of $\mathrm{NH}_{3}-\mathrm{N}$ and $\mathrm{TP}$

There was a certain correlation between the spatial variation and the temporal change of $\mathrm{NH}_{3}-\mathrm{N}$ concentration. The temporal changes of $\mathrm{NH}_{3}-\mathrm{N}$ in 12 catchments out of 13 catchments were significantly influenced by PWA. Therefore, the spatial variability of 


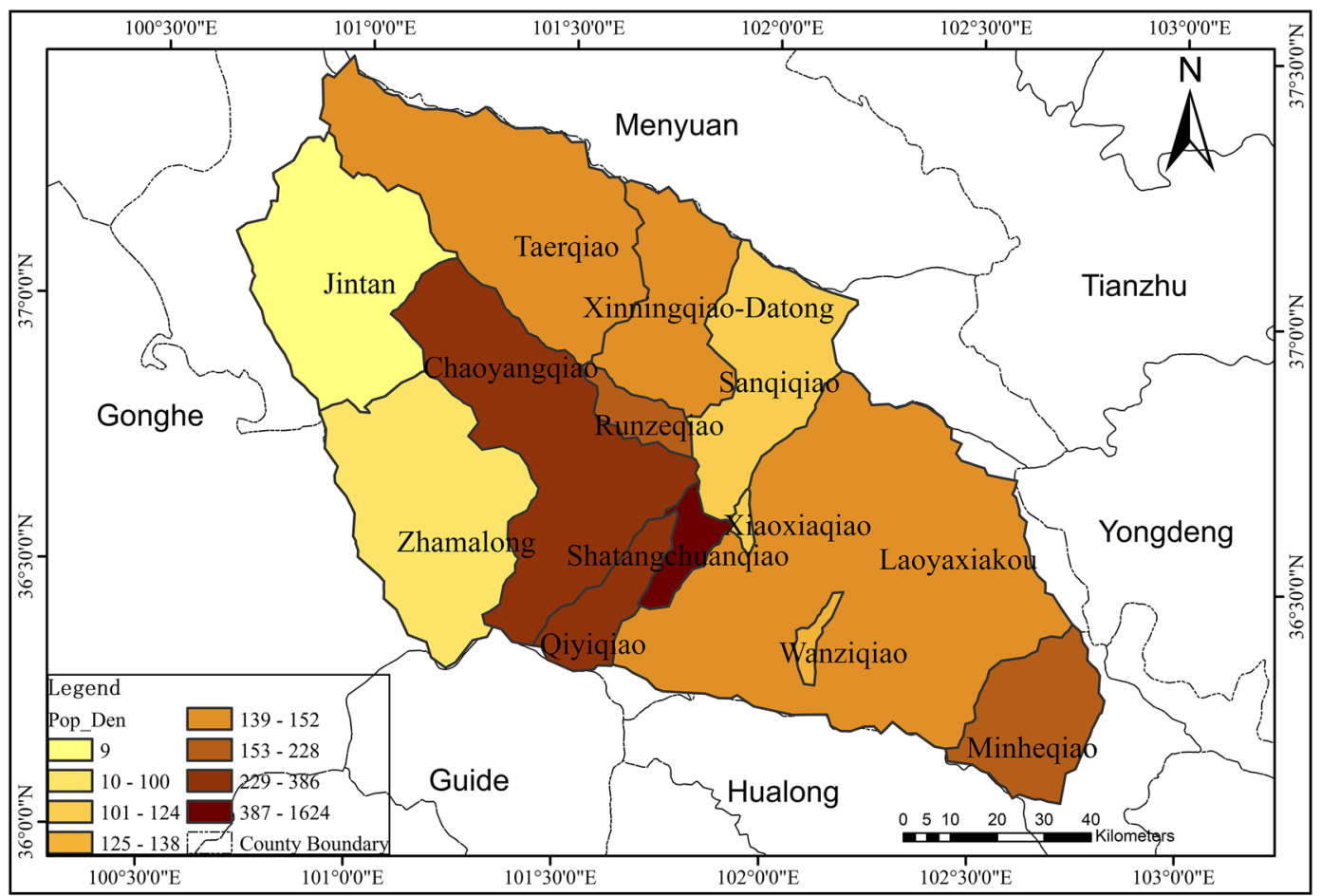

Fig. 9 Distribution map of population density in each catchment of Huangshui River basin

$\mathrm{NH}_{3}-\mathrm{N}$ concentration was also affected by PWA to some extent. The natural attributes of the watershed (topography, land use) are closely related to the factor HI. According to Yu et al. (2020), the large-scale vegetation restoration engineering in Loess Plateau since 1990s converted slope farmlands into forests or grasslands. This indicated that the land use change can be reflected by HD of the catchments to some degree. Considering the distinct influences of land use types on water contaminant concentrations, the relevant factor HI could be the significant factor for spatial variation of $\mathrm{NH}_{3}-\mathrm{N}$. The intensity of socioeconomic development and industrial structure layout of a basin both correlated with PSI, which contributes a lot to point sources of ammonia nitrogen pollution discharge. According to incomplete statistics, more than $70 \%$ of the industrial and mining enterprises in Qinghai Province are distributed in the Huangshui River basin, which is called the "Mother River" of Qinghai. Therefore, PSI in the Huangshui River basin undoubtedly contributes significantly to the spatial variation of ammonia nitrogen in this basin, which was similar with the conclusion of $\mathrm{Xu}$ et al. (2019a). The spatial variability of $\mathrm{NH}_{3}-\mathrm{N}$ concentration was mainly affected by the three factors: PWA, HI and PSI, which were similar to the findings of Ai et al. (2015) and Rattan et al. (2017) (Figs. 9, 10, and 11).

The certain correlation also existed between the spatial variation and the temporal change of TP concentration. The temporal change of TP in 11 catchments out of 13 catchments was significantly affected by PWA. Thus, the spatial variability of TP concentration was also affected by PWA obviously. Similar to the research of Zhou (2012), the sources of total phosphorus pollution load in Huangshui River Basin from 1997 to 2000 were mainly domestic, industrial wastewater, and fertilizer use, followed by livestock and poultry breeding. It showed that the total phosphorus pollution load of the secondary and tertiary industries was higher than that of the primary industry. Moreover, most of the sewage treatment plants and polluting enterprises in the basin are located along the river or close to the river net (Fig. 12). This type of discharge belongs to point source pollution, which may explain that the spatial variation 


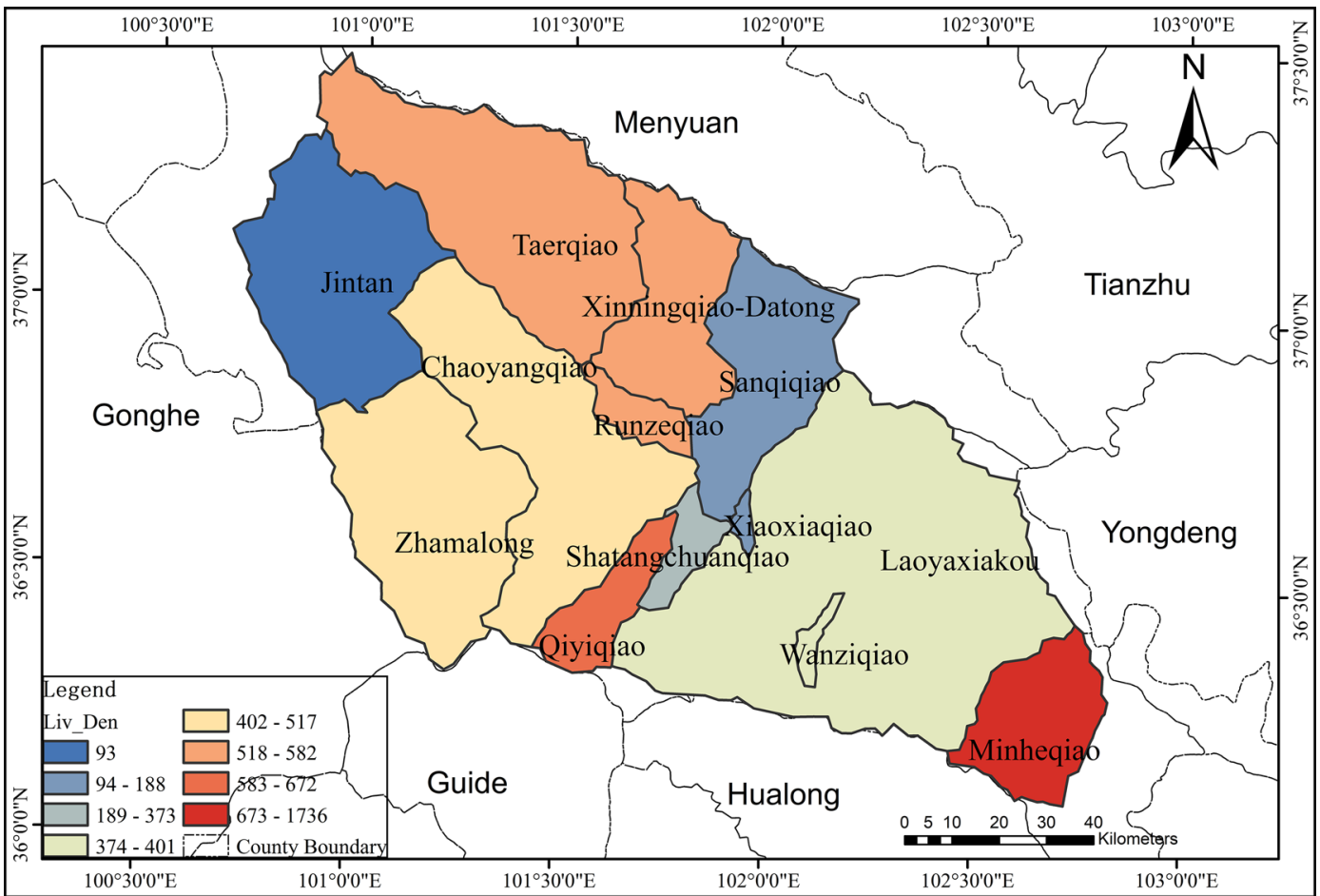

Fig. 10 Distribution map of livestock density in each catchment of Huangshui River basin

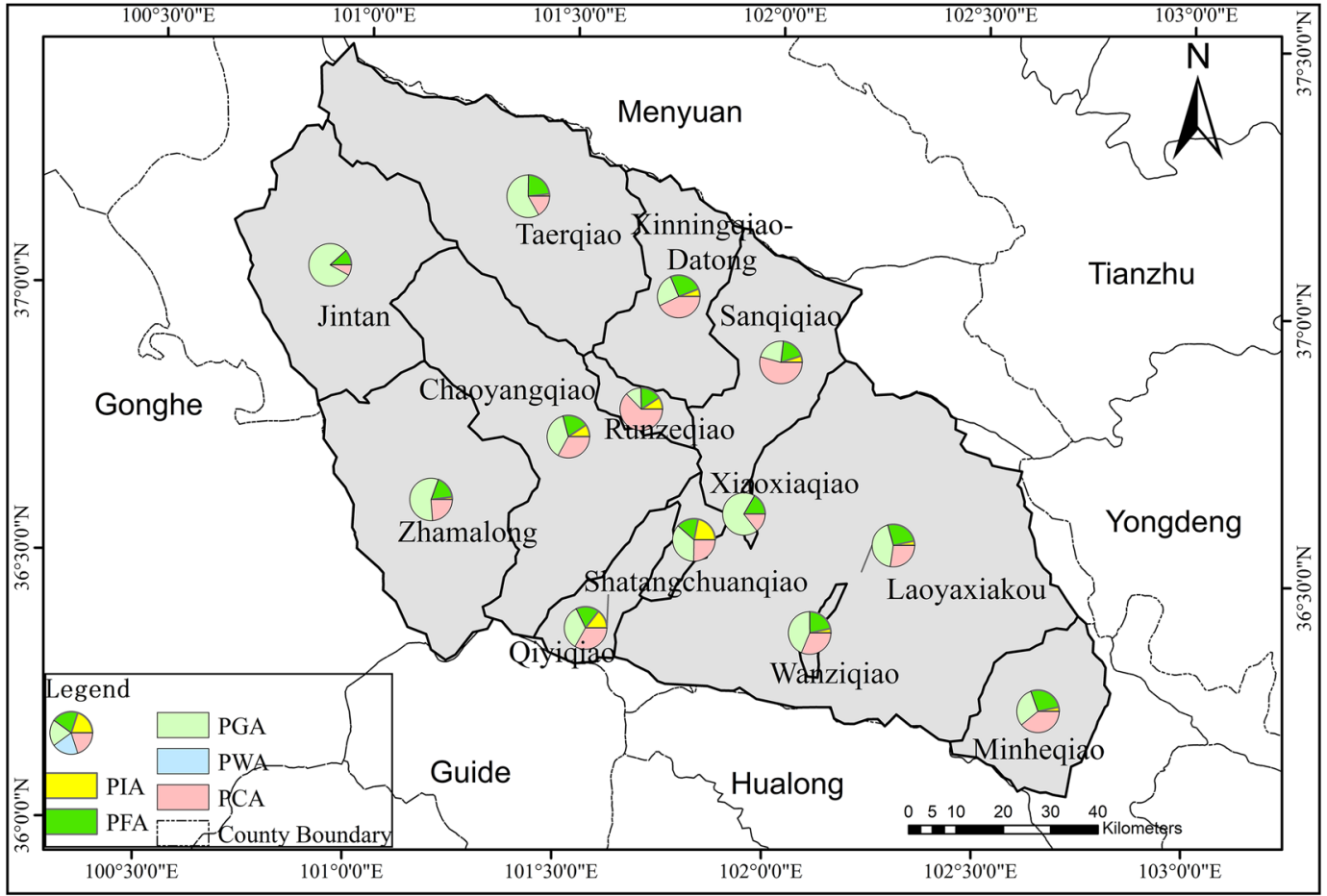

Fig. 11 Proportion of area of main land use types in each catchment of Huangshui River basin 


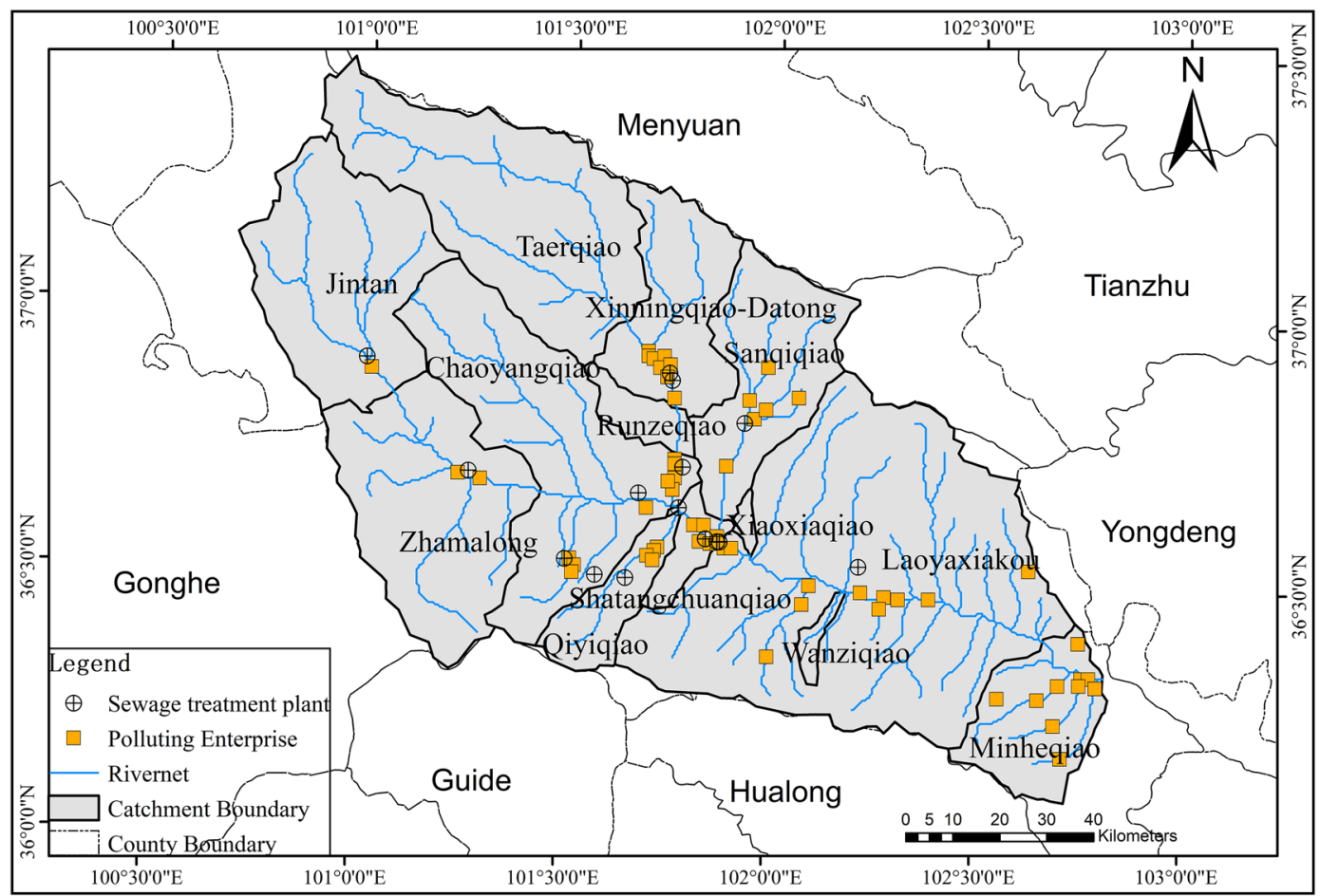

Fig. 12 A preliminary statistics of sewage treatment plants and polluting enterprise distribution in Huangshui River basin

of total phosphorus concentration was significantly affected by PSI and PTI. It also indicated that socioeconomic activities, especially $\mathrm{NH}_{3}-\mathrm{N}$ and $\mathrm{TP}$ discharge from the secondary and tertiary industry, have become a serious problem for the entire basin.

\section{Conclusions}

In this study, 4 out of 7 catchments in the middle reaches of the Huangshui River basin were found to have a larger number of mutations of $\mathrm{NH}_{3}-\mathrm{N}$ (>4) through the M-K test. The catchments in the upstream and downstream areas except Jintan and Taerqiao had fewer mutations of $\mathrm{NH}_{3}-\mathrm{N}$ and TP. The cluster analysis results of $\mathrm{NH}_{3}-\mathrm{N}$ and TP of all catchments were similar according to hierarchical agglomerative cluster analysis. The concentration of $\mathrm{NH}_{3}-\mathrm{N}$ and TP in the upstream and at the outlet of the basin has a higher possibility to meet the Class III standards for surface water bodies in GB3838-2002) (CSEPB, 2002).
This study showed that although the Huangshui River Basin was located in the upper reaches of the Yellow River, the influences of rainfall-runoff relationship on spatiotemporal changes of $\mathrm{NH}_{3}-\mathrm{N}$ and TP in its sub-basins were limited. Only the temporal change of $\mathrm{NH}_{3}-\mathrm{N}$ in Jintan catchment in the upstream area was significantly affected by runoff coefficient. Based on PLSR, land use types and socioeconomic development were the two main categories of factors which affect the temporal changes of $\mathrm{NH}_{3}-\mathrm{N}$ and $\mathrm{TP}$ in Huangshui River basin, of which PWA, PIA, and PPI were the top three independent factors for most catchments in the middle reaches. The temporal variations of $\mathrm{NH}_{3}-\mathrm{N}$ and TP in the large majority (12/13 of total catchments for $\mathrm{NH}_{3}-\mathrm{N}, 11 / 13$ for $\mathrm{TP}$ ) of all catchments were significantly affected by PWA. In the middle reaches of the Huangshui River basin, the temporal variations of $\mathrm{NH}_{3}-\mathrm{N}$ and TP in most catchments $(6 / 7$ of total catchments for $\mathrm{NH}_{3}-\mathrm{N}, 5 / 7$ of total catchments for TP) were also significantly affected by PIA and PPI. The temporal variation characteristics of TP in 
other catchments were significantly affected by PCA and PGA factors. The spatial variation of $\mathrm{NH}_{3}-\mathrm{N}$ was mainly affected by PWA, HI, and PSI. The spatial variation of TP was significantly affected by PWA, PSI, and PTI. The conclusions of this study may provide a reference for the control and management of nitrogen and phosphorus pollution in similar upstream river basins.

Funding This research was supported by the National Key Research and Development Project (Grant No. 2017YFA0605004), National Science Fund for Distinguished Young Scholars (Grant No. 51725905), National Key Research and Development Project (Grant No. 2016YFA0601503), and National Science Fund for Young Scholars (Grant No. 51709277).

Open Access This article is licensed under a Creative Commons Attribution 4.0 International License, which permits use, sharing, adaptation, distribution and reproduction in any medium or format, as long as you give appropriate credit to the original author(s) and the source, provide a link to the Creative Commons licence, and indicate if changes were made. The images or other third party material in this article are included in the article's Creative Commons licence, unless indicated otherwise in a credit line to the material. If material is not included in the article's Creative Commons licence and your intended use is not permitted by statutory regulation or exceeds the permitted use, you will need to obtain permission directly from the copyright holder. To view a copy of this licence, visit http://creativecommons.org/licenses/by/4.0/.

\section{References}

Ai, L., Shi, Z. H., Yin, W., \& Huang, X. (2015). Spatial and seasonal patterns in stream water contamination across mountainous watersheds: Linkage with landscape characteristics. Journal of Hydrology, 523, 398-408. https://doi. org/10.1016/j.jhydrol.2015.01.082

Al-Murairi, N., Abahussain, A., \& El-Bettay, A. (2014). Spatial and temporal characterizations of water quality in Kuwait Bay. Marine Pollution Bulletin, 83(1), 127-131.

Alvarez-Cobelas, M., Angeler, D. G., \& Sanchez-Carrillo, S. (2008). Export of nitrogen from catchments: A worldwide analysis. Environmental Pollution, 156(2), 261-269.

Buendia, C., Bussi, G., Tuset, J., Vericat, D., Sabater, S., \& Palau, A. (2016). Effects of afforestation on runoff and sediment load in an upland Mediterranean catchment. Science of the Total Environment, 540, 144-157.

Carrascal, L. M., Galvan, I., \& Gordo, O. (2009). Partial least squares regression as an alternative to current regression methods used in ecology. Oikos, 118(5), 681-690.

Chen, Q., Mei, K., Dahlgren, R. A., Wang, T., Gong, J., \& Zhang, M. H. (2016). Impacts of land use and population density on seasonal surface water quality using a modified geographically weighted regression. Science of the Total Environment, 572, 450-466.

CSEPB (Chinese State Environment Protection Bureau). (2002). Environmental Quality Standards for Surface Water (GB3838-2002).

Cui, X., Huang, C. Z., Wu, J. P., Liu, X. H., \& Hong, Y. G. (2020). Temporal and spatial variations of net anthropogenic nitrogen inputs (NANI) in the Pearl River Basin of China from 1986 to 2015. PLoS One, 15(2), e022868.

Dupas, R., Minaudo, C., Gruau, G., Ruiz, L., \& GascuelOdoux, C. (2018). Multidecadal trajectory of riverine nitrogen and phosphorus dynamics in rural catchments. Water Resources Research, 54(8), 5327-5340. https://doi. org/10.1029/2018WR022905

Fathian, F., Dehghan, Z., Bazrkar, M. H., \& Eslamian, S. (2016). Trends in hydrological and climatic variables affected by four variations of the Mann-Kendall approach in Urmia Lake basin, Iran. Hydrological Sciences JournalJournal Des Sciences Hydrologiques, 61(5), 892-904.

Guo, D., Lintern, A., Webb, J. A., Ryu, D., Liu, S., \& BendeMichl, U. (2019). Key factors affecting temporal variability in stream water quality. Water Resources Research, 55(1), 112-129. https://doi.org/10.1029/2018WR023370

Han, Q., Tong, R. Z., Sun, W. C., Zhao, Y., Yu, J. S., \& Wang, G. Q. (2020). Anthropogenic influences on the water quality of the Baiyangdian Lake in North China over the last decade. Science of the Total Environment, 701, 134929.

He, S., Qin, T. L., Liu, F., Liu, S. S., Dong, B. Q., \& Wang, J. W. (2019). Effects of slope ecological restoration on runoff and its response to climate change. International Journal of Environmental Research and Public Health, 16(20), 4017. https://doi.org/10.3390/ijerph16204017

Hobbie, S. E., Finlay, J. C., Janke, B. D., Nidzgorski, D. A., Millet, D. B., \& Baker, L. A. (2017). Contrasting nitrogen and phosphorus budgets in urban watersheds and implications for managing urban water pollution. Proceedings of the National Academy of Sciences of the United States of America, 114(16), 4177-4182.

Huang, G. R., Li, K. M., Zeng, X. H., Hu, H. Y., \& Ren, X. W. (2014). Watershed non-point source pollution load accounting. (1st ed., pp. 40-45). Science Press.

Jabbar, F. K., \& Grote, K. (2019). Statistical assessment of nonpoint source pollution in agricultural watersheds in the Lower Grand River watershed, MO, USA. Environmental Science and Pollution Research, 26(2), 1487-1506.

Lee, J. W., Lee, S. W., An, K. J., Hwang, S. J., \& Kim, N. Y. (2020). An estimated structural equation model to assess the effects of land use on water quality and benthic macroinvertebrates in streams of the Nam-Han River System, South Korea. International Journal of Environmental Research and Public Health, 17(6), 2116.

Li, C. L., Filho, W. L., Wang, J., Yin, J., Fedoruk, M., \& Bao, G. (2018). An assessment of the impacts of climate extremes on the vegetation in Mongolian Plateau: Using a scenariosbased analysis to support regional adaptation and mitigation options. Ecological Indicators, 95, 805-814.

Li, C. W., Zhang, H. Y., Hao, Y. H., \& Zhang, M. (2020). Characterizing the heterogeneous correlations between the landscape patterns and seasonal variations of total nitrogen and total phosphorus in a peri-urban watershed. Environmental Science and Pollution Research, 27(27), 34067-34077. 
Liu, F., Qin, T. L., Yan, D. H., Wang, Y., Dong, B. Q., \& Wang, J. W. (2020). Classification of instream ecological water demand and crucial values in a semi-arid river basin. Science of the Total Environment, 712, 136409.

Liu, X. C., Beusen, A. H. W., Van Beek, L. P. H., Mogollon, J. M., Ran, X. B., \& Bouwman, A. F. (2018). Exploring spatiotemporal changes of the Yangtze River (Changjiang) nitrogen and phosphorus sources, retention and export to the East China Sea and Yellow Sea. Water Research, 142, 246-255. https://doi.org/10.1016/j.watres.2018.06.006

Luedeling, E., \& Gassner, A. (2012). Partial least squares regression for analyzing walnut phenology in California. Agricultural and Forest Meteorology, 158, 43-52.

Luo, K., Hu, X. B., He, Q., Wu, Z. S., Cheng, H., \& Hu, Z. L. (2017). Using multivariate techniques to assess the effects of urbanization on surface water quality: A case study in the Liangjiang New Area, China. Environmental Monitoring and Assessment, 189(4), 174. https://doi.org/10.1007/ s10661-017-5884-8

Mayora, G., Schneider, B., \& Rossi, A. (2018). Turbidity and dissolved organic matter as significant predictors of spatio-temporal dynamics of phosphorus in a large riverfloodplain system. River Research and Applications, 34(7), 629-639. https://doi.org/10.1002/rra.3288

McGarigal, K., Cushman, S., \& Ene, E. (2015). FRAGSTATS v4: Spatial Pattern Analysis Program for Categorical Maps. Computer Software Program Produced by the Authors at the University of Massachusetts, Amherst. https://www. umass.edu/landeco/research/fragstats/downloads/fragstats_ downloads.html Accessed 27 September 2020.

Mellander, P.-E., Jordan, P., Shore, M., Melland, A. R., \& Shortle, G. (2015). Flow paths and phosphorus transfer pathways in two agricultural streams with contrasting flow controls. Hydrological Processes, 29(16), 3504-3518. https://doi.org/10.1002/hyp.10415

Min, M., \& Lee, W. S. (2005). Determination of significant wavelengths and prediction of nitrogen content for citrus. Transactions of the ASAE, 48(2), 455-461.

Ministry of Ecology and Environment of the People's Republic of China. (2018). China Environmental Status Bulletin. http:// www.mee.gov.cn/hjzl/sthjzk/zghjzkgb/ Accessed 26 September 2020.

Nielsen, A., Trolle, D., Søndergaard, M., Lauridsen, T. L., Bjerring, R., \& Olesen, J. E. (2012). Watershed land use effects on lake water quality in Denmark. Ecological Applications, 22(4), 1187-1200. https://doi.org/10.1890/11-1831.1

Nobre, R. L. G., Caliman, A., Cabral, C. R., Araujo, F. D., Guerin, J., \& Dantas, F. D. C. (2020). Precipitation, landscape properties and land use interactively affect water quality of tropical freshwaters. Science of the Total Environment, 716, 137044. https://doi.org/10.1016/j.scitotenv. 2020.137044

Oliveira, M. R., Branco, J. A., Croux, C., \& Filzmoser, P. (2004). Robust redundancy analysis by alternating regression. International Conference on Robust Statistics (ICORS 2003), Antwerp, Belgium, 13-18 Jul 2003.

Outram, F. N., Cooper, R. J., Sunnenberg, G., Hiscock, K. M., \& Lovett, A. A. (2016). Antecedent conditions, hydrological connectivity and anthropogenic inputs: Factors affecting nitrate and phosphorus transfers to agricultural headwater streams. Science of the Total Environment, 545, 184-199.
Pathak, D., Whitehead, P. G., Futter, M. N., \& Sinha, R. (2018). Water quality assessment and catchment-scale nutrient flux modeling in the Ramganga River Basin in north India: An application of INCA model. Science of the Total Environment, 631-632, 201-215. https://doi.org/10. 1016/j.scitotenv.2018.03.022

Pellerin, B. A., Wollheim, W. M., Hopkinson, C. S., McDowell, W. H., Williams, M. R., Vörösmarty, C. J., \& Daley, M. L. (2004). Role of wetlands and developed land use on dissolved organic nitrogen concentrations and DON/TDN in northeastern US rivers and streams. Limnology and Oceanography, 49(4), 910-918.

Pennino, M., Kaushal, S. S., Mayer, P. M., Utz, R. M., \& Cooper, C. A. (2016). Stream restoration and sewers impact sources and fluxes of water, carbon, and nutrients in urban watersheds. Hydrology and Earth System Sciences, 20(8), 34193439. https://doi.org/10.5194/hess-20-3419-2016

Rattan, K. J., Corriveau, J. C., Brua, R. B., Culp, J. M., Yates, A. G., \& Chambers, P. A. (2017). Quantifying seasonal variation in total phosphorus and nitrogen from prairie streams in the Red River Basin, Manitoba Canada. Science of the Total Environment, 575, 649-659.

Razmkhah, H., Abrishmchi, A., \& Torkian, A. (2010). Evaluation of spatial and temporal variation in water quality by pattern recognition techniques: A case study on Jajrood River (Tehran, Iran). Journal of Environmental Management, 91(4), 852-860.

Reichwaldt, E. S., \& Ghadouani, A. (2016). Can mussels be used as sentinel organisms for characterization of pollution in urban water systems? Hydrology and Earth System Sciences, 20(7), 2679-2689.

Rodrigues, V., Estrany, J., Ranzini, M., de Cicco, V., MartínBenito, J. M. T., \& Hedo, J. (2018). Effects of land use and seasonality on stream water quality in a small tropical catchment: the headwater of Córrego Água Limpa, São Paulo (Brazil). Science of the Total Environment, 622623, 1553-1561.

Shi, W., Xia, J., \& Zhang, X. (2016). Influences of anthropogenic activities and topography on water quality in the highly regulated Huai River basin, China. Environmental Science and Pollution Research, 23(21), 21460-21474. https://doi.org/10.1007/s11356-016-7368-8

Srinivas, R., Singh, A. P., Dhadse, K., \& Garg, C. (2020). An evidence based integrated watershed modelling system to assess the impact of non-point source pollution in the riverine ecosystem. Journal of Cleaner Production, 246, 118963.

Wang, H. T., Ma, B., Tang, S. Z., Chen, Z. X., Li, L., \& Wang, J. L. (2019). Evaluation on the Status Quo of Water Environmental for the Upper and Middle Reaches of the Yarlung Zangbo River in the Low Water Period. Fresenius Environmental Bulletin, 28(5), 3696-3703.

Wold, S. (1995). PLS for multivariate linear modeling. In H. van der Waterbeemd (Ed.), Chemometric Methods in Molecular Design: Methods and Principles in Medicinal Chemistry. (pp. 195-218). Verlag-Chemie.

Xia, X. H., Zhang, S. B., Li, S. L., Zhang, L. W., Wang, G. Q., \& Zhang, L. (2018). The cycle of nitrogen in river systems: sources, transformation, and flux. Environmental Science-Processes \& Impacts, 20(6), 863-891. https://doi. org/10.1039/c8em00042e 
Xiao, R., Wang, G. F., Zhang, Q. W., \& Zhang, Z. H. (2016). Multi-scale analysis of relationship between landscape pattern and urban river water quality in different seasons. Scientific Reports, 6, 25250. https://doi.org/10.1038/srep25250

Xu, G. C., Li, P., Lu, K. X., Zhan, T. T., Zhang, J. X., Ren, Z. P., et al. (2019a). Seasonal changes in water quality and its main influencing factors in the Dan River basin. CATENA, 173, 131-140.

Xu, J., Jin, G. Q., Tang, H. W., Mo, Y. M., Wang, Y. G., \& Li, L. (2019b). Response of water quality to land use and sewage outfalls in different seasons. Science of the Total Environment, 696, UNSP 134014.

Yu, Y., Wei, W., Chen, L. D., Jia, F. Y., Yang, L., \& Zhang, H. D. (2015). Responses of vertical soil moisture to rainfall pulses and land uses in a typical loess hilly area, China. Solid Earth, 6(2), 595-608.

Yu, Y., Zhao, W. W., Martinez-Murillo, J. F., \& Pereira, P. (2020). Loess Plateau: from degradation to restoration. Science of the Total Environment, 738, 140206.

Zhang, J., Li, D. P., Gao, P., Tao, Y., Wang, X. M., \& He, X. H. (2011). Analysis of water quality factors influencing the speciation of inorganic nitrogen using GRA. Journal of Environmental Biology, 32(5), 641-644.

Zhao, Y., \& Karypis, G. (2005). Hierarchical clustering algorithms for document datasets. Data Mining and Knowledge Discovery, 10(2), 141-168.

Zhou, T., Wu, J. G., \& Peng, S. L. (2012). Assessing the effects of landscape pattern on river water quality at multiple scales: a case study of the Dongjiang River watershed, China. Ecological Indicators, 23, 166-175.

Zhou, W. (2012). Analysis of nutrient sources in Huangshui River Basin based on SWAT and nutrient pollution control measures. Master's thesis, Capital Normal University, Beijing, China.

Zhou, X. W. (2007). The study on the grey relational degree and its application. Master's thesis, Jilin University, Changchun, China.

Publisher's Note Springer Nature remains neutral with regard to jurisdictional claims in published maps and institutional affiliations. 